\title{
Tibulo y Menéndez Pelayo ${ }^{1}$
}

\author{
Juan Luis ArCAz PozO \\ Universidad Complutense de Madrid \\ arcaz@filol.ucm.es
}

Recibido: 9 de diciembre de 2012

Aceptado: 21 de diciembre de 2012

\section{RESUMEN}

En este trabajo se analiza la recepción de Tibulo en la obra de Marcelino Menéndez Pelayo (1856-1912) prestándose especial atención a las dos versiones que hizo de la elegía I 1 del poeta latino.

Palabras clave: Marcelino Menéndez Pelayo. Tibulo. Tradición clásica. Traducción.

ArCaz Pozo, J.L., «Tibulo y Menéndez Pelayo», Cuad. Fil. Clás. Estud. Lat. 33.1 (2013) 161-205.

\section{Tibullus and Menéndez Pelayo}

\begin{abstract}
This paper analyzes the Tibullian reception in the work of Marcelino Menéndez Pelayo (1856-1912) with special attention to the two versions made on the Latin poet's Elegy I 1.

Keywords: Marcelino Menéndez Pelayo. Tibullus. Classical Tradition. Translation.

Arcaz Pozo, J.L., «Tibulllus and Menéndez Pelayo», Cuad. Fil. Clás. Estud. Lat. 33.1 (2013) 161-205.

Sumario 1. Introducción. 2. El primer contacto con la obra de Tibulo. 3. La impronta de Tibulo en la poesía personal de don Marcelino. 4. Las traducciones de Tibulo. 4.1. La traducción de la elegía I 1 en tercetos. 4.2. La traducción de la elegía I 1 en cuartetos. 5. Tibulo en las obras de crítica filológica. 6. Referencias bibliográficas.
\end{abstract}

\footnotetext{
${ }^{1}$ Este trabajo se enmarca en el proyecto de investigación «Los poetas romanos en España: transmisión, interpretación y tradición literaria» (Ref.: FFI2011-29372) financiado por el Ministerio de Ciencia e Innovación. 


\section{INTRODUCCIÓN}

El interés que Marcelino Menéndez Pelayo (1856-1912) mostró por traducir a los clásicos, y en especial a los poetas latinos, se circunscribe a una época muy concreta de su vida y responde a una vocación por el mundo antiguo que, a la vez de haberse ido alimentando con el paso de los años, influyó decisivamente también en una incipiente, y no muy desarrollada después, labor de poeta. Como de alguna forma ya han destacado algunos trabajos dedicados precisamente a estas dos parcelas que holló el polígrafo santanderino ${ }^{2}$, este doble y temprano afán lo irá abandonando, no obstante, con el correr del tiempo a medida que otros ambiciosos proyectos de alta erudición, y los comprensibles intereses académicos que abrigaba nuestro estudioso, acaben por absorber toda su atención y cuidados. Pues, en efecto, la mayor parte de las traducciones de autores clásicos -casi siempre sueltas y ocasionales- y la práctica totalidad de sus poesías originales se insertan en el corto período de nueve años que va desde la fecha en que tenemos constancia de la primera de las versiones que, con apenas quince años, lleva a cabo en 1871, hasta la publicación de los últimos poemas personales y traducciones que fueron reunidos en la recopilación que bajo el título Odas, epistolas y tragedias apareció en $1883^{3}$.

Los gustos de Menéndez Pelayo en relación con la poesía latina fueron bastante variados, aunque su predilección de joven lector, de entusiasta novicio seducido por la lengua y las formas líricas de Grecia y Roma, se orientó muy tempranamente hacia los poetas de amor (Oroz 1965, pp.11-12). Entre los latinos, fueron Catulo, Virgilio (sobre todo el bucólico de los delicados pastores transidos de amor, no el épico), Horacio y Tibulo (aparte, aunque en menor medida, de Ovidio - del que tradujo, o más bien parafraseó, el pasaje de Píramo y Tisbe de las Metamorfosis- y Propercio) algunos de los vates romanos que atrajeron la atención del aún joven Marcelino y se convirtieron en el acicate de una vocación traductora la suya que modeló también, forjándola en los viejos odres, su precoz afición a las musas. La recopilación de las versiones que hizo y que dio a la luz en 1878 bajo el rótulo común de Estudios poéti$\cos ^{4}$ da buena fe de esta inicial empatía personal con todos ellos y evidencia el rastro que, como a fuego, llegaron a imprimir algunos de estos autores en aquel joven poeta de oficio recién estrenado.

El propósito del presente trabajo es, en el marco de estas preferencias, describir la especial relación que Menéndez Pelayo tuvo desde sus primeros años de estudiante -y que se prolongó hasta bastante tiempo después- con la poesía de Tibulo, un poeta al que el santanderino se aficionó bien pronto y a quien, desde esa doble vertiente de su íntima relación con el mundo clásico, dedicó parte de sus desvelos como traductor

${ }^{2} C f$. en especial R. Oroz (1956, pp.7-25) y S. de la Nuez Caballero (1961, pp.111-138), quien señala al respecto que «el quehacer poético de D. Marcelino pertenece a la época juvenil de su vida, que coincide con sus años de plenitud y devoción clasicista, que son decisivos en el gusto y en la forma de su producción poética» (p.112).

${ }^{3}$ Véase la referencia completa en Menéndez Pelayo (1883).

${ }^{4}$ Véase la referencia completa en Menéndez Pelayo (1878). 
y reservó también una pequeña parcela de su propia musa. Su rigor intelectual, no obstante, también se plegó al verso del cantor de Delia y no dejó en casi ninguna de sus obras de carácter literario de dejar constancia de la especial erudición que había acumulado, por placer y por afición, sobre la poesía y la figura del poeta latino. Vamos, por tanto, a trazar una semblanza de ese peculiar vínculo de don Marcelino con el elegíaco que se inicia, a la par que su vocación de filólogo clásico y su entusiasta admiración por Grecia y Roma, prácticamente en la niñez ${ }^{5}$.

\section{EL PRIMER CONTACTO CON LA OBRA DE TIBULO ${ }^{6}$}

En 1866 y con apenas diez años, un preadolescente Marcelino Menéndez Pelayo ingresaba en el Instituto Cantábrico de Santander para comenzar sus estudios de bachillerato. Durante los cinco años que entonces duraba esta etapa de la enseñanza secundaria, el avezado alumno que tanta erudición ya acumulaba inició su contacto con la lengua latina. Ésta formaba parte de las no muchas asignaturas que completaban el plan de estudios y, a pesar de que el latín sólo se encontraban como materia de estudio en los dos primeros cursos, el aprovechamiento del joven Marcelino fue, sin lugar a dudas, extraordinario, como muestran sus inmediatamente posteriores investigaciones en el campo de los estudios clásicos aun antes de haber comenzado, o al tiempo que los iniciaba, sus estudios superiores en la Universidad de Barcelona, continuados luego en la de Madrid y culminados, por fin, en la de Valladolid, lugar donde trabará contacto con el catedrático de literatura Gumersindo Laverde, con quien mantendrá frecuentes contactos epistolares a partir de 1874 y que tanto peso pareció tener, como veremos, en algunos cambios producidos en la simpatía que Menéndez Pelayo mostró siempre por la poesía de Tibulo ${ }^{7}$.

Pero fue allí, en Santander, y cuando el niño que era don Marcelino contaba con sólo un decenio de vida, donde a través de las imborrables enseñanzas y la constancia de su profesor de latín Francisco María Ganuza ${ }^{8}$-aparte de la evidente predispo-

\footnotetext{
${ }^{5}$ No es nuestro propósito destacar aquí la aportación de Menéndez Pelayo al desarrollo de los estudios clásicos en España, sino describir, como decimos, el vínculo intelectual y creativo que nuestro erudito tuvo con la obra de Tibulo desde sus primeros años de estudioso. Sobre lo primero, no obstante, existe ya abundante y completa bibliografía; véanse, entre otros, los estudios de Hernández Vista (1956), Pabón (1957), Lasso de la Vega (1958), Laín Entralgo (1963) y, más recientemente, Martín Puente (2010).

${ }^{6}$ Para la reconstrucción de este período de la vida de don Marcelino en su relación con Tibulo nos apoyamos fundamentalmente en los datos aportados por Sánchez Reyes (1974) y en la información recogida en su correspondencia particular editada por M. Revuelta Sañudo ( $c f$. Menéndez Pelayo 1982-1991). La consulta de las obras de Menéndez Pelayo la hemos realizado sobre la edición digital de las mismas alojada en la Biblioteca Virtual Miguel de Cervantes.

${ }^{7}$ Sobre la especial y fructífera relación entre ambos, véase Carballo Picazo (1956) y Bueno Sánchez (1990).

${ }^{8}$ El recuerdo imborrable de este primer maestro de latines acompañó a Menéndez Pelayo el resto de su vida, como puede comprobarse por las palabras que a él le dedica en una nota autobiográfica que envía a Clarín y que acompañaba a una carta enviada a éste el día 27 de septiembre de 1893, donde dice: «Estudié la segunda enseñanza en el Instituto de Santander, y tuve la fortuna de tropezar con un buen profesor de latín, humanista de verdad. Se llama D. Francisco María Ganuza, vive aún, aunque jubilado y muy caduco» (Menéndez Pelayo 1982-1991, vol.XII, carta 414).
} 
sición del que ya era un prodigio de memoria y madurez intelectual- comenzó a forjarse su gran pasión por los clásicos ${ }^{9}$ y a materializarse, en sorprendentes estudios y traducciones, la empatía visceral que el ilustre polígrafo santanderino sintió tan tempranamente y de manera muy especial por los poetas de Roma. Las enseñanzas y el empeño de Ganuza fueron más allá de esos dos años de estudios obligatorios de latín: el condescendiente catedrático de la materia pactó con el ya adolescente Marcelino continuar el aprendizaje de la lengua del Lacio más allá del horario escolar y de la enseñanza reglada, conviniendo con él, y con el permiso de su padre, don Marcelino Menéndez Pintado, a la sazón catedrático de matemáticas en el mismo instituto que Ganuza (y a quien en no pocas ocasiones su hijo lo sustituirá en algunas de sus clases), seguir avanzando en el estudio de los clásicos a través de las nuevas traducciones y lecturas que el maestro le proporcionaba en su propio domicilio aun después de haber completado los dos primeros cursos de bachillerato. La relación entre Ganuza y don Marcelino hubo de ser harto provechosa e íntima, pues no fueron pocos los libros del preceptor que pasaron, y allí se quedaron, a la biblioteca particular y entonces incipiente del futuro polígrafo.

En este contexto de inicial contacto y estudio de los clásicos se sitúa una anécdota muy interesante y que guarda un estrecho vínculo con las imitaciones y versiones que Menéndez Pelayo habrá de hacer pocos años después de esta época sobre la poesía de Tibulo. El episodio lo recoge el hermano de nuestro autor, Enrique Menéndez (E. Menéndez Pelayo 1922, p.13; citado por Sánchez Reyes 1974, pp.22-23), y en él nos cuenta cómo en el verano de 1868 el joven Marcelino acompañó al poeta y abogado santanderino don Tomás Agüero a visitar en su retiro de Miengo a José Posada Herrera, ilustre político ovetense que entre otros cargos llegó a ocupar el de ministro de Gobernación en los años 1858 y 1865 y el de embajador de la Santa Sede en este mismo año de 1868. Allí, mientras los dos amigos charlaban, el pequeño Marcelino se entretuvo en curiosear entre los libros de la nutrida biblioteca de Posada, circunstancia que no le pasó desapercibida al sagaz político que, en el momento de la partida, le ofreció al muchacho escoger el libro que más le interesara. Menéndez Pelayo no dudó en elegir una edición mignon de Catulo, Tibulo y Propercio que tantos buenos ratos le haría pasar y que fue a partir de la cual llevó a cabo las traducciones de Catulo y de Tibulo de las que nos vamos a hacer cuestión aquí, según diremos después.

No fue éste el único clásico que ingresó tan tempranamente en la biblioteca de aquel aventajado niño; en los anaqueles de su librería particular -ubicada al principio en uno de los estantes del aparador en que su madre guardaba la loza de casa- el propio Menéndez Pelayo consignó que había en este año de 1868, según una nota autógrafa conservada y que reproducen tanto su hermano Enrique Menéndez como M. Aguilar en la biografía de nuestro autor, un total de treinta y cuatro volúmenes, en-

\footnotetext{
${ }^{9}$ Aunque a esta época tan temprana pertenecen sus primeros y sólidos pasos en el aprendizaje del latín, sin embargo, no llegó a dominar la lengua griega, a pesar de haberla estudiado en su paso por Barcelona, hasta su ingreso en 1873 en la Universidad de Madrid, donde tuvo como maestro al catedrático don Lázaro Bardón Gómez.
} 
tre los que se encontraban las siguientes obras latinas: el ejemplar de Catulo, Tibulo y Propercio regalado por Posada, un Quinto Curcio, las obras completas de Ovidio, los comentarios de Johannes Minellius a Tristes y Pónticas, las Fleurs latines de Larousse (un diccionario de expresiones latinas con su correspondiente traducción al francés con noticia de qué autores galos las habían utilizado y que debió de publicarse en 1861 ó 1862) y el De officiis de Cicerón.

Las enseñanzas, pues, de Ganuza y el creciente interés de Menéndez Pelayo por la lengua latina, como demuestra su parva e inicial biblioteca, llevaron a un joven Marcelino de apenas quince años a ejecutar las primeras traducciones serias, por llamarlas así y para distinguirlas de sus esfuerzos de principiante, de estos autores nada más acabar sus estudios de bachillerato. De $1871^{10}$ data la traducción del pasaje relativo a Píramo y Tisbe de las Metamorfosis de Ovidio, realizada en octavas reales al igual que el poema heroico que empieza a escribir en la primavera de ese mismo año sobre D. Alonso de Aguilar en Sierra Bermeja y que terminará ya en Barcelona en 1875 , y de la Égloga VIII de Virgilio, realizada en tercetos y dedicada a su maestro Ganuza, a quien el padre de nuestro polígrafo se la remitió, por indicación del joven Marcelino, según consta en esta carta que le envió a su hijo el día 18 de octubre de 1871:

Querido Marcelinito: Tu carta nos ha llenado de satisfación, pues vemos que cada día estas mas contento y que los Catedráticos te van ya distinguiendo, segun yo esperaba. D. Francisco se ha alegrado mucho con el triunfo que has obtenido en Literatura latina, triunfo debido, en gran parte, á él, por el interés con que ha cuidado de tu instrucción.

Nada te habia dicho del juicio que habia formado Ganuza sobre la primera composición que nos has mandado, porque cuando se la dí me dijo que tenia que compararla con otras traducciones que él tenía, y como este año tiene bastantes lecciones y por otra parte él es un poco indolente, hasta ahora nada me había dicho: hoy al entregarle la Egloga me dijo que compararía las dos con las traducciones que él tiene, segun tu sabes, y que ya me diria su parecer, aunque desde luego suponia que estarian bien (Menéndez Pelayo 1982-1991, vol. I, carta 3).

Instalado en Barcelona y dispuesto a comenzar sus estudios universitarios en la ciudad Condal, el interés de Menéndez Pelayo por las cuestiones relativas a la traducción de los clásicos no hizo sino aumentar, como a tal efecto demuestra el hecho de que a raíz del conocimiento que tuvo - a través de su tutor y luego amigo en la universidad barcelonense José Ramón Fernández de Luanco- de la obra de Juan Antonio Pellicer titulada Ensayo de una biblioteca de traductores españoles, iniciara la empresa de su Biblioteca de traductores españoles, obra en la que llevó a cabo una tarea de compilación y también crítica de muy notable calado, y en la que podemos leer, según veremos luego, algunos de los atinados comentarios que escribiera a propósito de los distintos autores que hasta ese momento habían traducido a Tibulo (desde Fray Luis de León hasta Pérez del Camino, incluido él mismo).

\footnotetext{
${ }^{10}$ La traducción, realizada ya en Barcelona, a donde Menéndez Pelayo se trasladó para iniciar sus estudios universitarios, está fechada el día 16 de octubre de ese año de 1871.
} 
Una vez terminados los estudios universitarios en Valladolid en 1874, ciudad en la conoció al ya citado catedrático Gumersindo Laverde, volvemos a encontrar algunas muestras muy significativas del interés que desde tiempo atrás la obra del elegíaco había despertado en el espíritu rural y enamoradizo de don Marcelino. Más por esta empatía personal y propia de la edad que por otros motivos cabe entender la profunda influencia que la poesía del latino ejerció en los intereses poéticos primeros de nuestro polígrafo: lo vemos tanto en sus composiciones poéticas personales como en el empeño por pulir sin descanso la versión -la única que de las prometidas por él conservamos- de la elegía I 1 tibuliana.

\section{LA IMPRONTA DE TIBULO EN LA POESÍA PERSONAL DE DON MARCELINO}

En efecto, ya desde muy niño Menéndez Pelayo había dejado volar su imaginación por la senda de la poesía heroica cuando, según se ha dicho, con quince años emprendió la redacción de aquel poema épico sobre la participación de D. Alonso de Aguilar en el sofocamiento de la rebelión morisca de Sierra Bermeja. Pero es ahora, con diecisiete años y bien empapado de la poesía amorosa de Roma que tanto había leído en el ejemplar regalado por Posada (aquel que contenía la obra de Catulo, Tibulo y Propercio), cuando hace acto de presencia el amor y cuando los ecos y la afición por esos poetas más claramente se manifiestan ${ }^{11}$. A esta época corresponden los varios sonetos en castellano y la elegía en latín que dedicó a Isabel Menéndez, ya fuera escondiéndola bajo el pseudónimo de Belisa (anagrama de su nombre) o ya bajo el apelativo de Epícaris, una joven por la que sintió una profunda y no disimulada pasión desde la vez primera que la vio en las playas santanderinas. Tanto las composiciones castellanas como la latina no dejan lugar a dudas de que en ellas don Marcelino imprimió el sello que mejor conocía y se ajustaba a sus lecturas más íntimas ${ }^{12}$. Dos de los sonetos, por ejemplo, cuentan en su frontispicio con sendas citas de Tibulo (el que comienza «Cual suele por las puertas del oriente» la del v. 69 de la elegía I 1 y el que lo hace «Ensalce a Laura el amador toscano» la de los vv. 3-4 de la elegía IV 13 del Corpus Tibullianum) y revelan asimismo una impronta muy evidente de la lectura de los versos de amor de Catulo y los elegíacos.

Mucho más interés tiene para nuestro propósito la elegía escrita en latín: ésta, a la vez que muestra una especial querencia de don Marcelino por la figura de Tibulo, revela que su autor también conocía de muy primera mano la poesía de Ovidio, pues en ella hay un manifiesto esfuerzo por emular -aunque sin la sugerente carga erótica

\footnotetext{
${ }^{11}$ Sobre la poesía clasicista de nuestro autor, véase L. Alas (1887), G. Diego (1931), C. Eguía Ruiz (1917) y J. Bravo Vega (1998).

${ }^{12}$ Algo parecido señalaba S. de la Nuez al decir: «Las imitaciones poéticas de Menéndez Pelayo se pueden considerar como una continuación, o como una lógica derivación, de las lecturas y traducciones del poeta; efectivamente casi todas ellas llevan fechas iguales o cercanas a estas últimas. Como en el caso anterior dominan las imitaciones de clásicos latinos, sobre todo de Horacio, cuya influencia se difunde por casi todas las composiciones como sería fácil de demostrar por un simple cotejo» (S. de la Nuez 1961, pp.117-118).
} 
de su modelo- la elegía I 5 de Amores con algún otro eco del Ars amatoria y otros más de signo catuliano que no es ocasión de comentarlos ahora con todo el detalle que merecerían. Éste es el texto de la composición del santanderino y la correspondiente traducción que hemos realizado en dísticos castellanos:

Mihi dulcis amorum sedes, pulcherrima virgo,

Quae facie praestas venustiore deas,

Pedibus alternis digna memorari Tibulli,

Candidior lacte candidaque nive;

Dicam oculorum lumen velut astra micantium, Hecatae similium cum rupit illa nubes,

Et laxos crines capitis de vertice tortos, Qui pectus tegunt turgentiaque poma,

Fluctibus densiores humero jactantur utroque;

Tales Aphroditem flexus habere credo,

Talis caesarie fuerat formosa Lacaena,

Pergami exitium trojanique regis;

Talis Berenices coma super astra locata,

Callimachi ingenio, docte Catulle, tuo.

Singula quid referam? manus tornatiles ipsas,

Gracilesque pedes, incessumque divum,

Et leves risus, blandaque murmura linguae,

Purpureo in ore provocante basia.

Felix qui dulcem possit exaudire loquentem,

Oscula loquenti qui tibi rapiat, felix!

Felix qui possit nuptam te ducere lectum,

Fulmine contactus dummodo postea cadat!

Eres mi dulce morada de amor, oh galante doncella, tú que a las diosas ganar logras con más bella faz, digna de ser de Tibulo en sus versos alternos cantada, más blanca que el requesón y que la nieve al caer.

Como una estrella diré que es la luz de tu limpia mirada, a Hécate tan similar cuando las nubes cruzó,

y que tu suelto cabello se ondula desde la cabeza hasta tu escote tapar y tus manzanas en flor,

y por un hombro y el otro caer aún más prieto en sus ondas: tales guedejas, creo yo, tuvo Afrodita también.

Tal por su pelo atractiva fue entonces la que era de Esparta, ruina de Pérgamo al fin y del monarca de Ilión.

De Berenice el cabello tal fue colocado en los astros gracias al griego cantor, docto Catulo, y a ti.

¿Cómo decir cosa a cosa? Que son torneadas tus manos, algo pequeños tus pies, propio de dioses tu andar,

que tu sonrisa es ligera y es suave el rumor de tu lengua en esa boca rubí siempre incitando a besar.

¡Sea feliz quien te pueda escuchar mientras dulce le hablas, quien mientras hablas te dé besos que sea feliz! 
¡Sea feliz el que pueda llevarte de esposa a la cama, aunque cayera después muerto por rayo fatal!

La joven Epicharis a quien se describe en la elegía (según consta en el encabezamiento-Epicharis laudatur; ejus pulchritudo depingitur-y en la propia dedicatoria -«Elegía a I.M. »-) es Isabel Menéndez, destinataria, al igual que algunos sonetos, de esta suerte de síntesis de evocaciones literarias, por más que su autor pretendiera ajustarse con tino a la real hermosura de la muchacha. El impacto de los encantos de la bella Isabel en Menéndez Pelayo es una constante en esta su primera poesía personal, pues, en otros de los sonetos que escribió, la ponderación de su belleza y la impresión causada en el joven estudiante es también objeto central de los poemas. Incluso podría decirse que uno de ellos, redactado con anterioridad a la elegía, pudo ser la versión castellana que sirvió de base (al menos en sus estrofas finales) a la composición en latín. Dicho soneto, fechado el 10 de enero de 1875 (esto es, casi año y medio antes que la elegía en latín, de la que consta la fecha del 3 de agosto de 1876) describe de este modo el arrobo que el joven Marcelino sentía por ella:

Recibe de mis versos el presente debido a tu belleza soberana, en tus aras tal vez ofrenda vana, tal vez recuerdo de mi amor ardiente.

Yo vi, señora, tu beldad riente en la sonante playa laletana, donde eleva Favencia la romana hacia las nubes su murada frente.

Te vi, te amé, mi corazón fue preso entre los rayos de tus claros ojos, entre las redes de tu crencha hermosa;

¡Feliz quien pueda, de tus labios rojos, ebrio de amor, arrebatar un beso, y venga sobre mí la muerte odiosa!

Es fácil adivinar en los citados tercetos finales (donde alude a la luz de sus ojos, a su pelo, a los labios que incitan al beso y a la muerte sobrevenida a quien, feliz él, pruebe tanta dicha), un adelanto de la descripción de la joven que leemos en la elegía escrita en latín: así, respectivamente, su oculorum lumen velut astra micantium, sus laxos crines capitis de vertice tortos, / qui pectus tegunt turgentiaque poma, / fluctibus densiores humero jactantur utroque, su boca carmesí siempre provocante basia y la irremisible muerte para que el guste tal felicidad Felix... / oscula loquenti qui tibi rapiat... / fulmine contactus dummodo postea cadat!

Pero lo que realmente nos interesa aquí es que en la elegía escrita por Menéndez Pelayo -al igual que indirectamente en los sonetos- late el ideal amoroso de Tibulo que se caracteriza por ese melancólico anhelo de alcanzar lo que es ensoñación irrealizable, aunque lo descrito por el joven Marcelino tenga un claro refrendo en la realidad y así sea percibido desde su ardor juvenil, que ha preferido como modelo para enumerar los encantos de la inalcanzable doncella el patrón que le prestaba no el 
poeta de Gabios, sino Ovidio, pues por más que Isabel sea, en efecto, digna de los versos tibulianos (Pedibus alternis digna memorari Tibulli) y represente en sí misma, muy al estilo del poeta, todo el más puro amor que él siente (Mihi dulcis amorum sedes), la lista de las virtudes físicas que la adornan está hecha sobre la pauta ovidiana de Amores I 5 y los efectos del amor que en nuestro erudito inspira son émulos de los descritos por Catulo en su poema 51.

Cuando Menéndez Pelayo escribía estos versos, su relación con la poesía de Tibulo se había ido afianzando a través de la lectura constante de su obra y de la traducción, de ahí que no resulte nada extraño que esté tan arraigado, aunque sea sutil, el tibulianismo de su propia musa. Su dedicación más decidida, como decíamos antes, a la traducción de los clásicos a partir de 1871 eclosionó en favor de Tibulo tres años después. En todo este tiempo, el ya avezado latinista en que se había convertido el joven Marcelino no debió de abandonar la incesante lectura del lujoso ejemplar mignon que el político Posada había regalado a Menéndez Pelayo en aquella visita providencial a Miengo. No cabe ninguna duda de que la traducción que nuestro autor hizo de la elegía I 1 de Tibulo, y que está fechada el día 5 de enero de 1874, se llevó a cabo sobre el texto de ese preciso ejemplar que contenía la edición de los ya citados poetas aparecida en Londres en 1824 impensis G. Pickering ${ }^{13}$. Se trata de un lujoso volumen, de minúsculo tamaño (sus dimensiones son de $85 \times 55 \mathrm{~mm}$, lo que explica que los biógrafos de Menéndez Pelayo aludan al hecho de que solía llevarlo metido en el bolsillo de su chaleco ${ }^{14}$ ), al que en la nota con que acompañó la traducción, además de aludir en ella a otras ediciones y comentarios consultados, identifica como el texto seguido para su versión ${ }^{15}$.

\section{LAS TRADUCCIONES DE TIBULO}

La traducción de esta elegía I 1 de Tibulo fue publicada, junto con su poesía personal y las otras traducciones que llevó a cabo (tanto de clásicos como de otros autores modernos), en los ya citados Estudios poéticos que vieron la luz a mediados de 1878. Sin embargo, la traducción que se incluyó en este volumen recopilatorio no tiene nada que ver con la que Menéndez Pelayo hiciera en 1874 y muestra, además, una serie de supresiones y alteraciones en el texto traducido que, entre otras razones, no cabe justificar más que por la decisión personal de su autor que se dejó

\footnotetext{
${ }^{13}$ La dedicatoria de la edición al conde Spencer a la que alude Menéndez Pelayo en la nota de su traducción dice así: Viro optimo et honorabili Georgio Johanni comiti Spencer Elegos Latinae Musae et Amores DDD. G.P.

${ }^{14}$ Sánchez Reyes (1974, p.23): «Este librito, que se conserva en su Biblioteca de Santander, se lo guardó Marcelino en el bolsillo del chaleco, que bien le cabía por lo pequeño del volumen, y ya no se separó de él hasta que, a fuerza de manosearlo en todos los momentos libres, se lo aprendió de memoria».

15 «He seguido para este trabajo la correctísima edición de Catulo, Tibulo y Propercio, que dedicada al Conde de Spencer, se publicó en Londres 1824, impensis G. Pickering. En ella los dísticos presentaban una distribución muy distinta de la ordinaria. Lo mismo se observará en los tercetos de mi traducción. He consultado además la edición de C. Tauchnitz hecha en Leipzig, y el «Corpus poetarum latinorum», de Londres, 1713, además de otras impresiones y comentadores que no es del caso referir» (Menéndez Pelayo 1878, p.94).
} 
llevar por los comentarios que, a propósito de la poca moralidad de la materia traducida, le hizo saber, como veremos, su amigo Gumersindo Laverde. Vamos, pues, a trazar una mínima semblanza de cómo se llegó del texto original al editado en los Estudios poéticos y a detallar las grandes diferencias que se aprecian entre esas dos versiones.

Sabemos, como se ha dicho y a tenor de lo que Menéndez Pelayo confiesa a su amigo Antonio Rubió (con quien había entablado una íntima amistad durante sus estudios universitarios en Barcelona), que la traducción de esta elegía I 1 se realizó a principios de enero de 1874 en Santander ${ }^{16}$. Interesa destacar que el entusiasmo por Tibulo, refrendado en esta primera versión en tercetos, llevó a su autor a declarar la posibilidad de traducir el resto de elegías («acaso me anime á traducir las demás elegías del mismo poeta») cuando -así se lo dice don Marcelino a Rubió- «tenga tiempo y oportunidad para ello». Esta carta, fechada el 8 de enero de 1874, no debió llegar a su destinatario, pues casi un mes más tarde (el 17 de febrero del mismo año) el propio Menéndez Pelayo alude a la pérdida de la misiva y a su intención de hacerle llegar al amigo algunos de los tercetos de la traducción que está llevando a cabo:

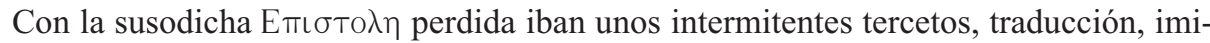
tación ó paráfrasis de la elegía 1. ${ }^{\mathrm{a}}$ del libro $1{ }^{\circ}$ del Albio Tibulo, caballero romano. Y como presumo que hayan corrido igual suerte que la carta en cuestión (...) he deliberado enviarte otra copia, que todavía no he acabado de hacer y que por lo tanto acompañará a la carta siguiente a esta (Menéndez Pelayo 1982-1991, vol.I, carta 87).

Por la correspondencia entre Menéndez Pelayo y Rubió queda claro que el santanderino no se acordó de cumplir la promesa de enviarle el texto de la traducción ya acabada, pues sabemos que nuestro erudito no se volvió a dirigir epistolarmente a su amigo hasta mayo de ese mismo año y lo hizo por cuestiones académicas que nada tenían que ver con sus avances en la traducción de Tibulo ${ }^{17}$.

No sabemos, pues, cuándo se terminó definitivamente la versión de la que don Marcelino hizo partícipe a su amigo Antonio Rubió, si es que realmente nuestro autor la iba haciendo intermitentemente, según indicaba a su colega de Barcelona. De cualquier manera, el caso es que justo un año después nos encontramos la constatación, y así se refleja en la fecha que la acompaña, de que esta traducción se terminó el día 5 de enero de 1874, según se indica en una carta datada el día 1 de enero de 1875 que Menéndez Pelayo envió a Gumersindo Laverde en la que, aprovechando el inte-

\footnotetext{
${ }^{16}$ Menéndez Pelayo (1982-1991, vol.I, carta 79): «Volviendo á mi estancia en Santander, te diré que durante ella he traducido en tercetos intermitentes la elegía 1. ' del libro 1. ${ }^{\circ}$ de Tibulo "Divitias alius fulvo sibi congerat auro"».

17 Así, en una carta fechada el 30 de mayo de 1874, se excusa a Rubió de este modo: «En cuanto á lo que me dices respecto á que en la carta, dirigida á tu papá, no hago la menor alusión á tu persona, te contestaré que lo hice así porque pensaba escribirte largamente, como en efecto lo hice pocos dias despues. Esta carta no debe haber llegado á tus manos, puesto que ( ¡ cosa horrible!) dices que la ultima que en tu poder tienes lleva la fecha del 19 de Febrero. De tales omisiones prometo indemnizarte largamente en el próximo verano» (Menéndez Pelayo 1982-1991, vol.I, carta 104).
} 
rés que previamente le había manifestado el catedrático de literatura por conocer la traducción tibuliana de Pérez del Camino -aparecida un año antes, en $1874^{18}$, le dice a su estimado profesor:

Con esta remito a Vd. la traducción ó, más bien, paráfrasis, que hice, há tiempo, de la elegía 1. ${ }^{a}$ de Tibulo . No la compare Vd. con el original, porque perderá el poco valor que tiene, si es que tiene alguno (Menéndez Pelayo 1982-1991, vol.I, carta 162).

Y, en efecto, don Marcelino acompaña la carta con el texto de la traducción en tercetos que había anunciado a Rubió y que más adelante analizaremos.

Los comentarios que acompañan el envío a Laverde («Al comienzo de la 2. a parte de esta elegía, hay un terceto asonantado, que hasta ahora no he acertado á corregir. Otras faltas más graves notará vd. en toda ella») dejan ver el carácter inacabado de la versión y la intención de su autor por seguir limando sus asperezas. Esta circunstancia es la que ha hecho posible la existencia de distintas copias en la Biblioteca de Menéndez Pelayo que ofrecen algunos cambios con respecto a la dada a conocer al propio Laverde ${ }^{19}$, aunque no tan abultados como los que presenta, según hemos dicho, la traducción incluida y publicada después en los Estudios poéticos.

Pese a las prevenciones de don Marcelino, la acogida de la versión por parte de Laverde no pudo ser más favorable, pues en contestación al autor de la misma le dice en una carta del 5 de enero de ese año:

Mi querido amigo: con el mayor placer recibí ayer su carta y la adjunta traduccion de la Elegia 1. ${ }^{a}$ de Tibulo, la cual me parece excelente y me hace desear que no sea su último trabajo del mismo género respecto á poetas latinos no traducidos todavía y en particular españoles (Menéndez Pelayo 1982-1991, vol.I, carta 163).

Mucho debió de animar a Menéndez Pelayo esta opinión de su amigo a tenor del empeño que siguió teniendo en su tarea de traducir a los clásicos. Tan sólo dos meses después, en marzo de 1875, el cántabro hace llegar a Laverde los frutos de su trabajo en esa dirección, comunicándole, y adjuntándole a la carta que le envía, las traducciones recién realizadas de una oda de Erina de Lesbos y de la elegía ovidiana a la muerte de Tibulo (Amores III 9), texto este último que sigue evidenciando, por un lado, el contacto con el poeta de Sulmona que no dejó de tener don Marcelino (como veíamos que ocurría en la elegía latina sobre los encantos de Epicharis escrita a la sombra de la I 5 ovidiana) y, por otro, la continua querencia que para con la figura de Tibulo y su poesía seguía manteniendo viva. Pero también esta versión ovidiana denota un cambio en los hábitos traductores de nuestro erudito que más

\footnotetext{
18 Véase la referencia completa en Tibulo (1874).

${ }^{19}$ Incluso ésta cuenta en la carta manuscrita con un par de cambios anotados por el propio remitente: se ha tachado en el v. 1 de la traducción la lectura 'busque' que volcaba inicialmente el congerat tibuliano y se ha sustituido por 'junte' y en el v. 9 se ha eliminado un originario 'jardines' que ha sido sustituido por 'confines'.
} 
tarde veremos reflejarse en la versión de la elegía I 1 del de Gabios recogida en los Estudios poéticos: la sustitución del empleo del terceto por el cuarteto para su traducción ${ }^{20}$.

Meses después, en septiembre de ese año de 1875, nuestro autor le comunica a Laverde la intención de publicar una recopilación de sus traducciones de poesías líricas. Y aunque parece haber abandonado el propósito que confesara más de un año atrás a su colega Antonio Rubió acerca de acometer la traducción completa de Tibulo, en su horizonte de expectativas se encuentra dar a luz una traducción más, aparte de la de I 1 ya realizada, del poeta de Gabios. En efecto, entre la lista de autores griegos y latinos que formarían parte de su florilegio se encuentra la siguiente relación de poetas y textos específicamente latinos que tiene previsto recoger: de Lucrecio la invocación a Venus del comienzo del De rerum natura, de Catulo el epitalamio (poema 62) y la elegía al sepulcro de su hermano (poema 101), de Ovidio la elegía a la muerte de Tibulo (Amores III 9), de Virgilio la Égloga X, de Horacio las odas I 5 y 12, de Petronio un fragmento en verso, de Prudencio el himno en loor de los mártires de Zaragoza, de Propercio la elegía IV 1 y, en lo que nos interesa, de Tibulo las elegías I1 y 3.

No todos los textos citados por Menéndez Pelayo fueron después incluidos en sus Estudios poéticos, bien porque desestimó la oportunidad de hacerlo o bien porque no llegó a realizar las traducciones previstas, si es que sólo se trataba de un proyecto por hacer. El caso es que de las traducciones aludidas no se encuentran en la recopilación publicada en 1878 -así como tampoco en la posterior de 1883- ni la Égloga X de Virgilio, que tal vez equivocara con la VIII (que sí se encuentra en ella y es aquella que había versionado en sus inicios como traductor y dedicara a su maestro Ganuza), ni la elegía IV 1 de Propercio, ni, por supuesto, la que creemos que debe tratarse de la elegía I 3 de Tibulo, pues no es más explícito en ello la carta del erudito ${ }^{21}$.

${ }^{20}$ Menéndez Pelayo (1982-1991, vol.I, carta 190): «Con esta remito á vd. dos traducciones de mi cosecha. La primera es la de la oda de Erina de Lésbos eìs Rómen (á la Diosa de la Fuerza); la otra es de la elegía de Ovidio á la muerte de Tibulo. Dígame vd. qué tal le parecen. La primera está en sáficos como el original; la segunda en cuartetos endecasílabos, que en esta ocasion me han parecido preferibles á los tercetos».

${ }^{21}$ Menéndez Pelayo (1982-1991, vol.I, carta 230): «Tengo pensado reunir mis traducciones de poesías líricas, añadir algunas más y formar con ellas un tomo (semejante en forma y tamaño al de las Poesías de Valera) que titularé Estudios Poéticos. En él entrarán versiones del griego, del latin, del italiano, del inglés, del francés y del lemosin, teniendo de esta suerte la coleccion variedad, á falta de otro mérito (...) Del latin. Invocacion de Lucrecio - Epitalamio de Catulo y Elegía al sepulcro de su hermano - Dos elegías de Tibulo (la 1. ${ }^{\mathrm{a}}$ y la $\left.3 .^{\mathrm{a}}\right)$ - Una de Propercio $\left(1 .^{\mathrm{a}}\right.$ del libro $\left.4 .^{\circ}\right)$ - La de Ovidio á la muerte de Tibulo - La égloga décima de Virgilio - Dos odas de Horacio (á Pirra, á Clio) - Fragmento de Petronio - Himno de Prudencio en loor de los mártires de Zaragoza (como anuncio de la version completa)». Parece que esta elegía tibuliana le gustaba especialmente a Menéndez Pelayo, como puede deducirse por el comentario con que acompaña en la Biblioteca de traductores su reseña a la versión de Pérez del Camino: «Hállase este trozo concisamente vertido [se refiere a los versos iniciales de la elegía], y aun imita bien en lo posible el tono ternísimo del original, si es que son imitables aquellos versos dulcísimos, en que hasta la colocación de las palabras produce honda impresión en el alma: Abstineas, mors atra, precor; non hic mihi mater | Quae legat in moestos ossa perusta sinus. Non soror, Assyrios cineri quae dedat odores, | Et fleat effusis ante sepulchra comis. Recomendarse debe la lectura de Tibulo a los que afirman que el sentimiento melancólico fué desconocido antes del cristianismo; ¡como si los antiguos hubieran sido hombres de diferente especie que la nuestra! Lo que no existió antes del cristianismo, 
Pero Laverde, que con tanto entusiasmo recibiera la primera versión que Menéndez Pelayo había hecho de la elegía I 1, debió de empezar a no ver con buenos ojos la deriva pagana por la que don Marcelino se había encaminado en este entusiasmo suyo por traducir a los poetas antiguos. Según iba conociendo el material preparado por el cántabro, su aplauso inicial pasó a convertirse en contenido reproche por la licencia con que el erudito santanderino despachaba sus versiones. Y así se lo hizo saber en una carta fechada el 28 de mayo de 1876 :

No tengo á mano las composiciones en que noté algunos rasgos peligrosos; pero recuerdo que eran la elegía de Tíbulo, el Epitalamio de Cátulo y sobre todo el idilio de Teócrito, y no sé si tambien una imitacion de V. El idilio es donde hallé lo mas grave (Menéndez Pelayo 1982-1991, vol.II, carta 29).

Como puede verse, la reprobación de Laverde, aparte de afectar al texto de Catulo y al idilio teocriteo de «Las hechiceras», va dirigida contra la traducción de la elegía I 1 de Tibulo y contra una «imitación de usted» que no ha de ser otra que la elegía latina ya vista con la que el santanderino celebraba los encantos de la joven Isabel Menéndez. Sorprende, en el caso de Tibulo, la adustez y arbitrariedad de Laverde para tildar de «peligroso» el inocente poema del de Gabios, pues ni siquiera por los cambios operados en la versión que publicó definitivamente en los Estudios poéticos podemos entender cuál era el peligro allí visto. Y la sorpresa es mucho mayor, si cabe, en el caso de la cándida elegía en latín escrita en pleno fervor de la adolescencia y al abrigo de sus íntimas lecturas clásicas.

El comentario de Laverde, no obstante, fue acatado por don Marcelino, que en una carta de 25 de enero de 1878 le confirma a su amigo, medio año antes de salir a la calle la edición de sus poesías y traducciones líricas, la aceptación de la amputación y modificaciones que le había sugerido:

Cediendo al cabo á tus consejos, he suprimido en un idilio de Teócrito ocho versos que presentaban un cuadro algo libidinoso, y he reformado otros cuatro ó cinco en una elegía de Tibulo, dejándolos de manera que ni por el pensamiento ni por la frase, ofenden ya los castos oídos (Menéndez Pelayo 1982-1991, vol.III, carta 17).

La recopilación, en efecto, se publicó en las citadas fechas con un prefacio de Leopoldo Augusto de Cueto, Marqués de Valmar, en el que, junto a la excelsa valoración que hace del vigor intelectual del amigo y de su ponderada mesura frente a los excesos de la poesía y la ficción, se sorprende de que el erudito haya incluido en esta obra a «vates livianos como Safo y Teócrito, obscenos como Catulo y Petronio, impíos como Lucrecio y Byron» y que sus preferencias literarias se hayan encaminado hacia «el paganismo antiguo... y el paganismo moderno», sin dar cabida alguna -sal-

o existió sólo en algunas almas privilegiadas, fué la vaga y melancólica aspiración a lo infinito, la creencia de que el mundo es valle de expiación y de lágrimas, que sólo de pasada habitan los desterrados de la Jerusalén celeste. La melancolía tibulina está por el contrario mezclada con elementos profanos, terrenos, y a veces repugnantes. Pero no nos incumbe entrar ahora en cuestiones tan hondas, propias de un libro de crítica filosófica, y no de unos apuntamientos bibliográficos» (Menéndez Pelayo 1952-1953, vol.IV, pp.52-53). 
vo rara excepción- a textos y autores más acordes a la moral cristiana. Pero el prologuista disculpa con amistoso cariño la deriva tomada por el gusto de don Marcelino, deudor en todo caso del ardor juvenil que por su edad aún manifiesta:

La predilección pagana es evidente, pero no hay que ver en ella ni sombra siquiera de impiedad, de impureza, de escepticismo, ni de audacia. Es simplemente la predilección literaria del estudiante entusiasmado, del mozo helenista, que bebió el sentimiento de lo bello en las más nobles y mágicas fuentes estéticas que ofrece la historia del mundo (Menéndez Pelayo 1878, p.15).

Tampoco el examen y comentario de Cueto encuentra nada que reprobar -salvo la elección del verso para traducir la poesía antigua, algo contra lo que se manifiesta el prologuista $^{22}$ - en la pericia del erudito cántabro para esquivar los escollos que hubieran podido contravenir los pudorosos principios que el autor del prólogo defiende:

No se precia por cierto de osado en estas materias nuestro querido joven. Para convencerse de ello, basta parar la atención en los pasajes escabrosos y comparar la versión con los textos respectivos. Siempre que frisan éstos con lo impío o con lo impúdico, Menéndez suprime o atenúa y modifica todo aquello que, traducido con fidelidad escrupulosa, podría lastimar los sentimientos que han nacido en las sociedades modernas de otros principios, de otras creencias y de otras costumbres (Menéndez Pelayo 1878, p.15).

Pero el «paganismo literario» del que habla el Marqués de Valmar a propósito de Menéndez Pelayo viene a ser una vocación estética en absoluto contraria al rigor moral que se le supone a su autor, de tal modo que su acercamiento a la licenciosa literatura antigua y moderna puede ser comparado, como el propio Cueto hace, al que Dante o fray Luis mostraron, desde la más estricta prudencia cristiana, con los autores y textos antiguos ${ }^{23}$.

Ciertamente, la sensualidad que el Marqués achacaba a los textos traducidos por Menéndez Pelayo quedaba más a la vista por sus propios comentarios que por lo que podía leerse en la traducción del santanderino ${ }^{24}$, como muy acertadamente le señaló

${ }^{22}$ Menéndez Pelayo (1878, pp.14-15): «No hay duda; esta literatura de las traducciones poéticas de la antigüedad es ardua y arriesgada; casi me atrevo a decir imposible. Si la traducción es absolutamente fiel (filológicamente se entiende), ni las palabras modernas alcanzan a dar a la poesía el color y la intención de las antiguas, ni el vulgo de los lectores puede comprender, sentir y admirar. Si es libre y desembarazada, quedan desnaturalizados por fuerza el texto y el espíritu antiguo: la versión es entonces una temeridad o una caricatura o una calumnia literaria».

${ }^{23}$ Más contundente en su defensa del pagano Menéndez Pelayo se mostró Juan Valera en la respuesta al prólogo de Cueto que se incluye también en los Estudios poéticos de 1878 (y lo fue aún más en la presentación que hizo de la edición de sus poesías y traducciones de 1883). El novelista e ilustre amigo de don Marcelino pondera con indisimulado fervor por el colega el exquisito cuidado que ha puesto en la elección de composiciones para traducir y el modo con que ha velado «tan púdicamente algún pasaje un poco vivo, al verterle a nuestro idioma, que casi todo lo podría leer la más recatada doncella sin comprender lo pecaminoso» (Menéndez Pelayo 1878, p.28).

${ }^{24}$ Menéndez Pelayo (1982-1991, vol.IV, carta 40): «La carta prólogo del señor Cueto es un escrito interesante y ameno como todo cuanto sale de tan privilegiada pluma. Recalca demasiado sobre la sensualidad obscena de los poetas antiguos, de donde resulta que algunas páginas del moralizador prologuista son quizá 
Miguel Antonio Caro a éste en una carta de 18 de septiembre de 1879 en la que le agradece el envío de un ejemplar de los Estudios poéticos y le hace partícipe de algunas observaciones en torno a los autores traducidos. Nos interesa en particular lo que le indica a propósito de la elegía tibuliana, pues Caro, tras haber elogiado muy sinceramente la poesía personal del polígrafo, hace una valoración no muy positiva de esta versión de Tibulo a cargo de don Marcelino:

No es posible reunir todas las cualidades, y aun éstas suponen defectos correlativos. V. traduce muy bien a Horacio y traduciría con felicidad a Homero; pero interpretando a Tibulo no acierta a expresar las delicadezas de sentimientos del cantor de Delia. En sus epístolas a Horacio y a sus amigos de Santander, está V. en su terreno, y no le pese mantenerse en él; hemos abusado del género llorón, y el rumbo noble que V. sigue se conforma con ciertas tendencias de reaccion poética, en todo sentido saludable (Menéndez Pelayo 1982-1991, vol.IV, carta 40).

Como puede imaginarse, el juicio del reputado traductor virgiliano no debió infundir muchos ánimos en el entusiasmado erudito cántabro para retomar su antiguo empeño de traducir a Tibulo, pues, además, a medida que iba introduciéndose en los absorbentes círculos académicos y en una más sesuda investigación se iba apagando su inspiración poética y su juvenil afición por los poetas de amor de Grecia y Roma. En cualquier caso, Menéndez Pelayo no volvió a traducir, que sepamos, verso alguno de Tibulo después de la publicación de los Estudios poéticos y compuso muy poca poesía personal tras esta aventura lírica, según puede comprobarse por las no muchas composiciones posteriores a 1878 que se incluyen en las Odas, epístolas y tragedias de $1883^{25}$.

Obvio es que la traducción que había leído Caro no era aquella que le hiciera llegar a Laverde y que tan encendidos elogios suscitó en el catedrático de literatura, sino la que había transformado por entero, cambiando incluso el tipo de estrofa en que fue traducida, y de la que había limado todas aquellas obscenidades que no gustaban al admirado censor. ¿Cuál era el tenor, pues, de estas traducciones y cuáles eran sus tan grandes diferencias? Vamos a verlo a continuación.

\subsection{LA TRADUCCIÓN DE LA ELEGÍA I 1 EN TERCETOS}

Comenzando por la realizada en primer lugar, aquella de la que le habló a su amigo Rubió y que envió a Laverde, hemos de señalar que se trata de una traducción íntegra, sin ningún tipo de supresión, del texto de la elegía I 1 a partir de la citada edición del ejemplar mignon de G. Pickering ya comentado. Con respecto a esto, Menéndez Pe-

menos decentes que las piezas mismas que censura. El comentario sobre Safo es más peligroso a la inocencia que la oda misma de la poetisa Lesbiana».

${ }^{25}$ En realidad, Menéndez Pelayo, aunque no se prodigara en exceso como poeta, siguió cultivando su musa al abrigo de los clásicos latinos, bien que el modelo y la inspiración para estos poemas de su última etapa lírica va a ser Horacio, tanto en su influjo directo como a través de la lectura que de él hizo fray Luis ( $c f$. S. de la Nuez 1961). 
layo indicaba en la nota que acompañaba a la versión que el texto seguido no presentaba la disposición habitual de los dísticos (entendemos que habitual con respecto a otras ediciones al uso) y que había consultado, además de ésta, la teubneriana de Tauchnitz $^{26}$ y la del Corpus poetarum latinorum ${ }^{27}$, entre otras obras que no cita.

Lo cierto es que el texto de la edición de Pickering, y el de las otras que dice haber consultado, coincide con el que habitualmente leemos en las más importantes ediciones de Tibulo posteriores a la edición de Heyne de 1755 (el primero que restauró en cierta medida el texto tibuliano tras la edición de J.J. Escalígero) ${ }^{28}$, por lo que don Marcelino ha de estar refiriéndose a cualquiera de las muchas ediciones realizadas en los siglos XVIII y XIX, sobre todo francesas, que mostraban las arbitrariedades que el humanista galo había cometido con el poeta de Gabios en su nefasta edición de 1577 . Algo similar podemos deducir por lo que apostilla al respecto de las ediciones tibulianas en el comentario con que en la Biblioteca de traductores acompaña su referencia a la traducción de Pérez del Camino, para la que Menéndez Pelayo estima que el traductor ha seguido un texto distinto del editado y, en lo que nos interesa, deudor de la línea inaugurada por el citado Escalígero y bien conocido, según se ve y luego comprobaremos, también por él:

En cuanto al texto latino que acompaña al Tibulo de Camino, sólo diremos que aunque abunda en graves yerros, no es tan malo como la generalidad de los que salen de nuestras imprentas. Sólo hubiéramos deseado que en lo posible se adoptase el texto, que siguió el traductor, que fué a nuestro entender el de Barbon, u otro muy semejante, pues de lo contrario se expone al lector a gravísimas confusiones, viendo en contradicción palmaria el original y la versión. Las ediciones de Tibulo hechas en el siglo pasado abundan en variantes, a veces no poco sustanciales, y hasta presentan trastrocados algunos pasajes (Menéndez Pelayo 1952-1953, vol.IV, p.56) ${ }^{29}$.

Por otro lado, esta traducción en tercetos, aparte de ser publicada mucho tiempo después, a finales ya del siglo XX, en la edición que M. Revuelta Sañudo preparó de las cartas que Menéndez Pelayo intercambió con sus colegas y amigos (recuérdese que la presente traducción iba como apéndice a la misiva que don Marcelino envió a Gumersindo Laverde el 1 de enero de 1875$)^{30}$, fue dada a conocer por vez primera

${ }^{26}$ Cf. Tibulo (1829). El texto de la elegía I 1 está en las pp.85-87.

${ }^{27}$ Cf. Tibulo (1721). El texto de la elegía I 1 se encuentra en la p.495.

${ }^{28}$ Para las aportaciones de Heyne al texto de Tibulo, véase Moya (1985, pp.81-83). Algunos de los rasgos que caracterizan la caprichosa edición tibuliana de Escalígero pueden verse también en Moya (1985, pp.73-74).

${ }^{29}$ Entendiendo que el nombre Barbon que cita Menéndez Pelayo sea una errata por Barbou, como creemos, la edición a la que se refiere salió a la luz en París en 1743 y muestra, en efecto, las diferencias señaladas con respecto a lo que habitualmente leemos en las ediciones más rigurosas de Tibulo. Véase la referencia completa de dicha edición en Tibulo (1743).

${ }^{30}$ Cronológicamente, el lector de las obras editadas de Menéndez Pelayo tuvo acceso a la segunda de las versiones que vamos a comentar -la realizada en cuartetos e incluida en sus Estudios poéticos-antes que a esta primera en tercetos. Téngase en cuenta que, como decimos, el texto de la versión original de 1874 estaba recogido en la referida carta que don Marcelino envió a Laverde un año después de haberla llevado a cabo. Por su lado, la publicación en papel del Epistolario de Menéndez Pelayo fue realizada por Manuel Revuelta Sañudo, en 22 volúmenes, entre los años 1982 y 1991 en Madrid, bajo los auspicios editoriales de la Fundación Universitaria Española. 
-que sepamos- y con el acompañamiento de la referida nota, en el diario La Catalu$\tilde{n} a$ el 4 de septiembre de 1909 con una breve presentación (bajo el título «El joven traductor de Tibulo M. Menéndez Pelayo») de Jaime Barrera. La publicación formaba parte del homenaje que a través de este diario le brindó al erudito cántabro la intelectualidad catalana a la que tanto contribuyó también la ciencia de don Marcelino. El comentario de Barrera a la traducción no contiene sino elogios y parabienes por la «equilibrada serenidad» del maduro juicio crítico que el santanderino manifestó siempre desde su más tierna mocedad, como, en opinión de Barrera, muestra esta traducción realizada por un Menéndez Pelayo «casi niño» y «maravillosamente vertida en rítmicos tercetos castellanos que dan fe elocuente del profundo conocimiento de la lengua difícil del Sacio [obvia errata del texto en lugar de Lacio], por parte de un joven á quien puso Dios en las cántabras tierras para que fuese pasmo de su siglo y lazo de espiritual unión entre las naciones ibéricas»». El texto editado se corresponde con el que acompañaba la citada carta a Laverde, algo ciertamente sorprendente por haberse publicado bastantes años atrás, en los Estudios poéticos de 1878, como ya hemos dicho, esta misma traducción pero en su versión en cuartetos ${ }^{31}$.

La factura de esta traducción realizada en tercetos es muy distinta, y no sólo por el cambio del soporte versal, a la otra que luego comentaremos, aunque algunos versos de la primera versión se han mantenido sin cambios en la segunda. En líneas generales, y a pesar del gran esfuerzo del joven Menéndez Pelayo, la traducción resulta un tanto anárquica en cuanto a los principios generales que la rigen (pues es literal en unas ocasiones y completamente libre en otras) y no puede considerarse muy lograda si lo que buscaba don Marcelino era ofrecer, a la par que un texto poéticamente 'recreado', una fiel aproximación a la elegía de Tibulo, como convenientemente prevenido señalaba en la referida nota con la que en sus Estudios poéticos acompañaba a la traducción (aunque allí se publicara la realizada en cuartetos, tan distinta a ésta pero de muy semejante cariz a ella en cuanto a su relativa literalidad) ${ }^{32}$ :

Esta traducción fué uno de mis primeros ensayos y en tal concepto es sobrado parafrástica, desigual escabrosa e incorrecta. Me he encariñado, no obstante con algunos trozos, y por eso la conservo. En la traducción de esta elegía no me he ceñido literalmente al texto latino, sino que he procedido con alguna libertad acercándome más que al rigor de la versión interlineal a la exactitud que cabe en la parafrástica (Menéndez Pelayo 1878, p.94).

\footnotetext{
${ }^{31}$ Salvo que fuera intención del autor de la nota, como parece sugerirse, sacar del anonimato aquellos escritos que indubitablemente habían de pertenecer a la pluma de don Marcelino y que, dado el poco parecido de esta traducción en tercetos con la publicada en los Estudios poéticos, creyera que no se había publicado todavía.

32 Esta alusión a la traducción en tercetos en la nota que acompaña a la traducción en cuartetos publicada en los Estudios poéticos es lo que hace decir a R. Oroz que Menéndez Pelayo se había equivocado al identificar el metro de su versión: «Sólo hay que advertir que en esta nota, se le deslizó un lapsus calami al declarar que su traducción está hecha en tercetos, cuando en verdad consta de cuartetos, en que, conforme a la regla rima el primer endecasílabo con el cuarto y el segundo con el tercero» (Oroz 1956, p.15). Obviamente el error que cometió don Marcelino no fue equivocar la estrofa de su versión, sino el no haber adaptado la nota en cuestión a la nueva versión en cuartetos cuando ésta estaba pensaba para la versión en tercetos.
} 
Son, en este sentido, muy frecuentes las amplificaciones a partir del texto original (lo que hace, por añadidura, aumentar el número de versos que presenta la elegía tibuliana $)^{33}$, y no porque hayan podido considerarse necesarias para aclarar algún punto oscuro del texto latino o para perfilar mejor su vuelco al castellano, sino porque es evidente que el traductor se ha recreado en estas partes ofreciendo mucha materia poética de su propia cosecha, de tal manera que, en ocasiones, la traducción es con más frecuencia una imitación que una traducción propiamente dicha (como ya advertía el propio erudito al considerar esta aproximación suya a la elegía de Tibulo «sobrado parafrástica»). De ello hay numerosos ejemplos a lo largo de la versión, y el comentario de un par de casos bien significativos puede bastar para confirmarlo.

Una notable amplificación la encontramos nada más comenzar el texto, pues los tres primeros dísticos de la elegía latina son vertidos por Menéndez Pelayo en dieciséis versos (los cinco primeros tercetos más el primer verso del sexto) que esponjan con extrema generosidad la parte de la composición de Tibulo referida a la intranquilidad que atenaza a los que optan por vivir contrariamente a lo que propugna el poeta, según éste resalta muy a las claras a través del juego de la priamel que le ofrece la contraposición alius... ego en I 1, 1-6:

Divitias alius fulvo sibi congerat auro

Et teneat culti ingera multa soli,

Quem labor assiduus vicino terreat hoste

Martia cui somnos classica pulsa fugent:

Mi mea paupertas vitae traducat inerti,

Dum meus assiduo luceat igne focus.

En este caso, puede verse cómo la contención para no hinchar el original sólo se aprecia al comienzo de la versión, que es donde acaso podamos ver un esbozo de las intenciones de don Marcelino (propósito conseguido, no obstante, en otras partes de su traducción) por ajustarse a la norma de verter cada dístico en un terceto castellano. Así, al casi seguimiento de esa intencionalidad que se aprecia en la adaptación de los vv. 1-4 de Tibulo, le sigue una significativa recreación del v. 3, cuyo sentido se desarrolla en la versión del cántabro durante otros cuatro versos más (hasta el primer verso del cuarto terceto), según podemos apreciar a poco que comparemos el correspondiente pasaje de la traducción con el texto original:

Junte otro las riquezas y el tesoro,

Mil yugadas de suelo cultivado;

Duerma feliz sobre montones de oro.

Y su tranquilo sueño sea turbado

Por el bélico son de los clarines,

Y del lecho levántese azorado.

\footnotetext{
${ }^{33}$ Frente a los 78 versos (treinta y nueve dísticos) con que cuenta la elegía latina nos encontramos con 154 (cincuenta tercetos más un cuarteto final) en la versión de don Marcelino, es decir, prácticamente el doble.
} 
Vea asaltar de su heredad los fines,

Y las armas del bárbaro enemigo

Talen á sangre y fuego sus confines.

Sufra de sus riquezas el castigo,

Yo no escucho el sonido de la trompa.

Parece que al traductor le ha parecido poca la amenaza expresada por Tibulo y ha creído conveniente apuntalarla con esa amplificación de cuño personal (aunque lógicamente inspirada en el texto original y compatible con lo dicho por el poeta latino), de igual forma que en otro lugar de su traducción (allí donde vierte los vv. 59-60 de la elegía tibuliana en que el de Gabios imaginaba cómo sería el último instante de su vida en compañía de Delia):

\section{Te spectem, suprema mihi cum venerit hora,}

Te teneam moriens deficiente manu,

Menéndez Pelayo, redoblando el dramatismo que se insinúa en la estampa pintada por Tibulo, construye una escena mucho más patética que la del elegíaco y nos presenta a la amada, transida de dolor y entre ayes de pena, aferrada al lecho del moribundo poeta, pronto ya a expirar:

Y cuando llegue á mí la hora postrera,

Véate yo postrada ante mi lecho

Derramar una lágrima sincera.

Y desahogando el oprimido pecho,

Invocar el auxilio sobrehumano,

Con lamento que hiera el alto techo.

Y llamando á los Dioses, aunque en vano,

Faltándome las fuerzas y el aliento,

Estrecharte, al morir, con débil mano.

Hay, como hemos dicho, otros muchos más casos de amplificaciones realizadas en la traducción que toman como pretexto algún dístico o verso del texto latino para engrosar, por vía de la aportación lírica del traductor, algunos de los pasajes de la elegía que le hubieron de parecer a don Marcelino cargados de mayor intensidad. Pero, según se señaló, hay también otros lugares de esta versión -aunque no muchos- en que podemos encontrar una estricta correspondencia entre dístico y terceto, conforme a lo que es habitual en aquellas traducciones que optan por verter la estrofa de la elegía latina en los correspondientes tercetos castellanos. Pueden servirnos de ejemplo también un par de casos.

El primero de ellos podemos verlo en la traducción de los vv. 15-16 de Tibulo, allí donde el poeta, de acuerdo a la religiosidad que caracteriza todo su corpus y resplandece más que en ningún otro en esta elegía, ofrece a la diosa Ceres un adecuado y modesto presente tomado de su terruño:

Flava Ceres, tibi sit nostro de rure corona

Spicea quae templi pendeat ante fores, 
algo que queda perfectamente recogido - aunque con un cierto desorden con respecto a su disposición en el dístico latino- en este único terceto de la versión:

Florida espiga cogerá mi mano,

Dorada Ceres, para tu corona,

Que en rico templo penderá romano.

Del mismo modo, un segundo caso lo podemos encontrar un poco más adelante, en los vv. 21-22 de la elegía tibuliana, pasaje donde, nuevamente llevado por el escrúpulo religioso que muestra con los dioses del campo, el poeta alude a las ofrendas que, cuando su peculio se lo permitía, hacía a la divinidad y que ahora, en cambio, se han visto drásticamente recortadas:

Tunc vitula innumeros lustrabat caesa iuvencos,

Nunc agna exigui est hostia magna soli.

Y una vez más, de acuerdo a la norma aludida, el dístico se vierte consecuentemente en este flamante terceto:

Entonces una vaca yo ofrecía,

Y becerros sin número lustraba,

Una cordera es hoy la ofrenda mía.

Ambos ejemplos, igual que ocurre con los otros que podrían señalarse, no eran, desde luego, pasajes que por su contenido pudieran ofrecerle a don Marcelino un atractivo lírico que le sirviera de excusa para hinchar el texto original, al contrario de lo que sí ocurre con las amplificaciones señaladas y con la práctica totalidad de los demás engrosamientos que pueden encontrarse en su versión.

Pero, en cualquier caso, ya sea recurriendo al expediente de la amplificación o ya respetando puntualmente el estricto contenido del original, lo habitual es que la traducción permita su lectura con una meridiana claridad y discurra sin entorpecer el cabal entendimiento de lo que dice el texto latino, aunque hay algún pasaje que, tal vez por la impericia del novel traductor (según comprobamos al comparar estos lugares con los correspondientes de la más limada traducción en cuartetos) ${ }^{34}$, queda completamente oscurecido y falto de sentido en la versión castellana. Un caso significativo es el de los vv. 41-42 en que Tibulo, desde su postura de rechazo a las riquezas, afirma no ambicionar herencia alguna de sus antepasados en los siguientes términos:

Non ego divitias patrum fructusque requiro quos tulit antiquo condita messis avo.

El dístico, que no ofrece problema alguno ni de traducción ni de interpretación (de tal forma que podríamos entenderlo como «No busco yo las riquezas de mis padres

\footnotetext{
${ }^{34}$ Así, los vv. 41-44 que pasamos a comentar en la traducción en tercetos quedan de este modo en la realizada en cuartetos: «No ansío de mis padres la riqueza, / ni la opulenta troj de mis abuelos; / pobre mies satisface mis anhelos. / Descanse en pobre lecho mi cabeza».
} 
ni los frutos / que trajo la mies guardada a mi antiguo antepasado»), se vierte en un tortuoso terceto cuyo sentido se encabalga con la traducción del dístico siguiente (vv. 43-44: Parva seges satis est, satis est requiescere lecto, / si licet, et solito membra levare toro) que, a su vez, queda reducido a la mínima expresión de lo que en puridad dice («Una pequeña cosecha es suficiente, suficiente es descansar en el lecho / $\mathrm{y}$, si es posible, aliviar el cuerpo en la cama acostumbrada»). El resultado de la versión, que clarifica, aun simplificando, el segundo dístico pero hace incomprensible el sentido del primero, es una amalgama de ideas en las se pierde irremisiblemente el traductor al ofrecer esta interpretación del pasaje:

No de mis padres (por diversos casos

Perdidas) las riquezas ambiciono,

Que el tiempo se llevó con largos pasos.

No me deslumbra el esplendor de un trono;

Con pequeña heredad vivo contento,

Los paternos tesoros abandono.

En cuanto a los pocos nombres propios que aparecen en la elegía, no cabía mucho margen de error en la adaptación al castellano de los pocos que aparecen en ella. Con todo, además de incluir algunos que, conforme a las amplificaciones señaladas, obviamente no aparecían en el texto latino y sirven para concretar el original o son mera expansión de la idea que el erudito sospecha que está escondida en el texto que traduce (así el de Pan para explicar el agricolae...deo del v. 14 o los de Belona y Pomona que incorpora motu proprio cuando traduce el dístico de los vv. 17-18 dedicado a Priapo), hay un caso en que don Marcelino yerra, pero no parece que por desconocimiento, en la transcripción del nombre de la diosa Pales cuando interpreta el v. 36 (et placidam soleo spargere lacte Palem) por «y los dones á Palas consagrados», dándole a esta divinidad campesina de Roma el sobrenombre de la Atenea griega ${ }^{35}$.

Por otro lado, como decíamos antes, no es precisamente esta composición de Tibulo el más conspicuo y mejor ejemplo de elegía irreverente ni por su erotismo ni por su contenido ideológico, pues salvo la incitación a vivir el amor mientras se es joven que podemos leer al final de ella y la placentera sensación que el poeta describe, abrazado a Delia y recogido al calor del fuego, mientras fuera jarrea la lluvia, es sumamente difícil encontrar algo en verdad «peligroso», como opinaba Laverde, en ningún otro lugar, a no ser que las continuas referencias a los dioses Lares y a otras deidades campesinas molestaran a los ojos antipaganos del adusto y ultracatólico catedrático. Con todo, Menéndez Pelayo, según vimos, dijo haber hecho caso a las indicaciones de su amigo modificando aquellos versos hirientes que le había indicado el severo censor, aunque, en verdad, los cambios que introdujo en la traducción son a todas luces ilocalizables puesto que la adaptación en cuartetos es una variación completa de la realizada en tercetos y poco hay en esa segunda versión que permanezca inalterado

\footnotetext{
${ }^{35}$ En la versión en cuartetos, sin embargo, Menéndez Pelayo opta por deshacer la cuasi homonimia entre Pales y Palas al traducir, también mucho más literalmente, el citado verso de este modo: «y baño en leche y entretejo en flores / el ara de la Diosa labradora».
} 
con respecto a la primera. Lo que sí es significativo es que, aparte de las modificaciones que pudiera acatar y hacer don Marcelino según lo aconsejado por Laverde, hay varios pasajes que, no sabemos si por indicación de su colega o por propia iniciativa, y aun encontrándose en la hecha en tercetos, fueron suprimidos en la traducción en cuartetos. Ello no obstante y al margen de la omisión de estas porciones de texto, los riesgos que en realidad comportaba el poema tibuliano, como ocurría a propósito de los comentarios de Cueto que el colombiano Caro le hacía notar a nuestro polígrafo en la ya citada carta, parece que estaban más en la delicada suspicacia del rancio lector que en las intenciones de la vieja elegía.

Éstos fueron los pasajes suprimidos en la posterior traducción en cuartetos que, bien por llevar al extremo el juicio crítico de Laverde o por exclusiva decisión personal, según decimos, se encontraban vertidos así en la traducción en tercetos:

Tunc vitula innumeros lustrabat caesa iuvencos,

Nunc agna exigui est hostia magna soli.

Agna cadet vobis, quam circum rustica pubes

Clamet 'io messes et bona vina date'.

Iam mihi, iam possim contentus vivere parvo

Nec semper longae deditus esse viae.

(vv. 21-26)

Entonces una vaca yo ofrecía,

Y becerros sin número lustraba,

Una cordera es hoy la ofrenda mía.

Y si entónces un buey sacrificaba,

Al inmolaros hoy pobre cordero,

La campesina juventud gritaba:

«Dádnos, oh Dioses, con propicio agüero,

Granadas mieses y abundante vino».

Vivir contento en la pobreza quiero.

Hoc mihi contingat: sit dives iure, furorem

Qui maris et tristes ferre potest pluvias.

(vv. 49-50)

Esto tan solo mi ambicion pretende;

Quien sufre de la lluvia los rigores

Y sobre el ancho mar las velas tiende;

Quien arrostra los bélicos furores,

Este solo alcanzar puede riqueza,

Á precio de fatigas y dolores.

Illo non iuvenis poterit de funere quisquam

Lumina, non virgo, sicca referre domum.

(vv. 65-66)

¿Qué zagal, qué pastora de la sierra

Secos los ojos, tornará á su casa,

Viendo la urna, que mis restos cierra? 
Son, según puede comprobarse, pasajes todos en los que no hay atisbo alguno de 'peligro' moral como el que hubiera podido encontrarse, y así lo detectó Laverde, en el también censurado epitalamio de Catulo o en el idilio teocriteo sobre los que Menéndez Pelayo le había pedido también opinión cuando abrigaba el proyecto de publicar sus traducciones líricas. Lo más que podemos ver, y que pudo acaso obligar a don Marcelino a tomar la decisión de secluirlos, es que se trata de lugares que podían ofrecer una visión comprometida del traductor a ojos de un lector excesivamente remilgado: cualquiera que viera, por ejemplo, alguna complacencia del erudito con respecto a la descripción de los sacrificios lustrales que se mencionan en los vv. 2126 (dado el paganismo del que se le acusó por su entusiasta fervor por el mundo clásico), o que entendiera que podía existir alguna referencia al amor homosexual o promiscuo en la alusión de los vv. 65-66 a los jóvenes y muchachas a que Tibulo se refiere cuando habla de sus exequias (motivo que ya le hizo variar la traducción de un verso de Teócrito, como apunta Cueto en el prólogo a los Estudios poéticos ${ }^{36}$ ) o, quizá, que identificara como propia del traductor la falta de ambición y desidia que se expresa en los vv. 49-50, conforme al otium elegíaco al que el poeta latino aspira con tal de no verse apartado de Delia.

\subsection{LA TRADUCCIÓN DE LA ELEGÍA I 1 EN CUARTETOS}

La supresión de estos pasajes y los sustanciales cambios señalados (tanto por lo que se refiere a la forma como al contenido mismo de la versión -aunque paradójicamente se esté traduciendo el mismo texto latino-) son, en primera instancia, los rasgos más significativos que diferencian la adaptación realizada en tercetos de la que luego se publicó en cuartetos. Y aunque lo más llamativo sea, sin duda, la sustitución de una estrofa por otra, hay también otras importantes modificaciones que resultan tan llamativas como las omisiones de esos pasajes a que nos acabamos de referir.

Comenzando primeramente por la cuestión del cambio del cuarteto por el terceto para esta nueva versión del texto tibuliano, hay que señalar que el uso del primero es algo que ya Menéndez Pelayo había experimentado, antes de en esta elegía, en la traducción de la ovidiana de Amores III 9 publicada también en los Estudios poéticos de 1878. Es curioso constatar que la factura de esta versión de Ovidio en cuartetos coincide cronológicamente (pues es del 18 de marzo de 1875) con los comentarios que

\footnotetext{
${ }^{36}$ Así dice Cueto: «No se precia por cierto de osado en estas materias nuestro querido joven. Para convencerse de ello, basta parar la atención en los pasajes escabrosos y comparar la versión con los textos respectivos. Siempre que frisan éstos con lo impío o con lo impúdico, Menéndez suprime o atenúa y modifica todo aquello que, traducido con fidelidad escrupulosa, podría lastimar los sentimientos que han nacido en las sociedades modernas de otros principios, de otras creencias y de otras costumbres. Suprime, por ejemplo, en el idilio segundo de Teócrito, la parte lasciva y descompuesta de la extraña relación de amores que la desdeñada Simeta dirige a la Luna; y no habrá usted dejado de notar que cuando, en este mismo idilio, alude la hechicera a aquella fea y repugnante costumbre, contraria a cada paso en la literatura de la antigüedad greco-romana, Menéndez elude hábilmente la dificultad en este verso: «No sé de quién; mas vive enamorado». La duda que expresa Teócrito no es tan vaga» (Menéndez Pelayo 1878, pp.15-16).
} 
a propósito de la traducción de Pérez del Camino - muy favorables en relación al uso que del cuarteto hace en la versión de algunas elegías- rubrica don Marcelino el Viernes de Dolores de 1875 (esto es, el 19 de marzo de ese año) e incluye en su Biblioteca de traductores:

Usó Pérez de Camino en su versión de variedad de metros, procurando evitar el fastidio que pudiera producir una versión continuada en tercetos o en versos sueltos. Además de estas dos formas, generalmente empleadas en la versión de composiciones de esta índole, usó nuestro poeta con habilidad no escasa de los cuartetos endecasílabos, llegando a encerrar en ocasiones un dístico del original en dos versos castellanos (Menéndez Pelayo 1952-1953, p.52).

Es conveniente recordar que Menéndez Pelayo le decía a Laverde, sin dar mayores explicaciones por su parte y en fechas muy próximas a cuando llevó a cabo la traducción de la elegía ovidiana (a saber, en una carta que le envía, junto con la versión, seis días después de haberla hecho) ${ }^{37}$, que en esa ocasión había decidido servirse del cuarteto en lugar del terceto para su ejecución. Por el entusiasmo que nuestro erudito mostró al hablar de las versiones en cuartetos que había leído en la obra de Pérez del Camino (cuya traducción ya había revisado con cierta profundidad poco después de su publicación ${ }^{38}$ ) quizá podamos entender el motivo por el cual decidió en aquel momento -y conforme se materializa en su adaptación del texto de Ovidio- sustituir la estrofa usada en la primera versión, el terceto, por la que utiliza en la segunda, el cuarteto. La sucesión de fechas, al menos, avala este repentino cambio en sus preferencias: la traducción del burgalés es de 1874, la de la elegía ovidiana que hace don Marcelino está fechada el día 18 de marzo de 1875 y, por último, la data del comentario a la obra de Pérez del Camino es de un día después de haber acabado dicha traducción, es decir, del 19 de marzo, Viernes de Dolores, de ese mismo año. Es posible, por tanto, que al hilo de estas circunstancias nuestro erudito considerara que era mejor cambiar el cuarteto por el terceto para remodelar, no sabemos cuándo -aunque con absoluta seguridad después de principios de enero de 1875, fecha del envío de la adaptación en tercetos a Laverde- su primera versión de la elegía I 1 antes de publicarla entre las restantes y más elaboradas traducciones líricas que realizó.

Es evidente que, por lo que dice a propósito de estas versiones y por lo que vemos que fue la propia actividad de Menéndez Pelayo como traductor (de antiguos y de modernos), además de por lo que apostilla en los comentarios al respecto que aparecen recogidos en muchos lugares de su obra (especialmente en la Biblioteca de traductores, en la Bibliografía hispano-latina clásica y en los prefacios de algunas de las ver-

\footnotetext{
${ }^{37}$ Menéndez Pelayo (1982-1991, vol.I, carta 190): «Con esta remito á vd. dos traducciones de mi cosecha. La primera es la de la oda de Erina de Lésbos eìs Rómen (á la Diosa de la Fuerza); la otra es de la elegía de Ovidio á la muerte de Tibulo. Dígame vd. qué tal le parecen. La primera está en sáficos como el original; la segunda en cuartetos endecasílabos, que en esta ocasion me han parecido preferibles á los tercetos»».

${ }^{38}$ Dicha traducción de Pérez del Camino debió llegar a manos de don Marcelino, como muy tarde, en torno al mes de septiembre de 1874, pues en una carta fechada el 1 de octubre de ese mismo año le comunica a Laverde que ha recibido de manos de Alonso Martínez, sobrino del traductor y autor del prólogo, un ejemplar de la traducción (Menéndez Pelayo 1982-1991, vol.I, carta 139).
} 
siones de autores latinos que recopiló $\left.{ }^{39}\right)$, la decidida apuesta de don Marcelino por la traducción en verso de los textos poéticos es una cuestión que no admite discusión alguna y que él entendió como una actividad que había de correr pareja a su labor de poeta (como en la práctica así ocurrió). Menéndez Pelayo tradujo en verso a los poetas porque él se sentía poeta, y tal vez de ahí sea de donde procedan las tan acusadas desviaciones con respecto a los textos traducidos que pueden observarse en muchas de ellas, como es el caso de las dos que aquí nos ocupan. Aunque el cántabro se ejercitó en el uso de distintas estrofas para sus versiones de los autores clásicos de Grecia y Roma (bien de ascendencia antigua como la estrofa sáfica, bien propiamente romances como el terceto, el cuarteto o la octava), la opción que consideraba más apropiada, y que él no llegó a desarrollar por completo, era la del endecasílabo libre, según vemos que opina en aquellos casos en que comenta alguna traducción realizada por este procedimiento (Castro 2005, pp.212-213). Junto a esta opción, y a tenor de lo que vemos en la traducción de la elegía III 9 de Ovidio y en ésta de Tibulo publicada en los Estudios poéticos, don Marcelino debió de considerar también un estimable vehículo de traducción el cuarteto, al menos según lo veía en las adaptaciones de otros traductores, como es el caso de Pérez del Camino, de quien ya hemos visto que elogiaba con gran entusiasmo su habilidad para «encerrar en ocasiones un dístico del original en dos versos castellanos»».

En cualquier caso, Menéndez Pelayo, sea por los motivos que fuere, decidió cambiar el terceto por el cuarteto en esta versión y, asimismo, procuró rehacerla por completo modificando la práctica totalidad de los versos que inicialmente había traducido (aunque otros, como veremos, se resistieron al cambio), a la vez que alteró el orden de algunos dísticos con respecto a la edición que inicialmente siguiera. El resultado fue una traducción que, al haber reducido drásticamente el número de versos con respecto a la primera ${ }^{40}$ (no sólo por la supresión mencionada, sino porque evitó engrosar su versión con tanta alegría como lo hizo en aquélla), guarda algo más de fidelidad con el texto latino y amplifica, por tanto, bastante menos el sentido original.

Con respecto a la alteración operada por don Marcelino en los dísticos de esta versión en cuartetos, hay que señalar que no sólo se trata de un capricho del traductor (o que, al menos, es un capricho debido a otros condicionantes). Según hemos indicado antes, nuestro erudito comentó la recién aparecida traducción de Pérez del Camino en su Biblioteca de traductores y apuntó algunos datos muy interesantes sobre el texto seguido por el burgalés que resulta que a la postre también afectaron a esta traducción suya. Decíamos entonces que en la Semana Santa de 1875 Menéndez Pelayo firmaba la reseña a la obra de Pérez del Camino que había aparecido tan sólo un año antes, el mismo en que hacía la traducción en tercetos que hemos comentado sobre el texto de la edición de G. Pickering que tantas diferencias mostraba, en la ordenación de los dísticos, con respecto a aquellas ediciones que habían seguido la estela de la de J.J. Escalígero. Una de estas ediciones fue la que precisamente don Marcelino refiere como posible texto base para la traducción del burgalés: la editada en las prensas parisinas

\footnotetext{
${ }^{39}$ Véase, entre otros, Castro (2005, pp.205-226) y Martín Puente (2010, pp.252-254).

${ }^{40}$ La traducción en tercetos contaba con 154 versos; ésta en cuartetos sólo cuenta con 104.
} 
de J. Barbou en 1743. Sin embargo, Menéndez Pelayo hace notar que el texto latino ofrecido por Pérez del Camino no se corresponde con el seguido para su traducción, pues en la versión de don Norberto se traducen como dísticos de la elegía I 1 los vv. 67-80 de la I 2 tal y como aparecen en la citada edición de Barbou (y en muchas otras), pero que no se registran en el texto latino que acompaña a la traducción ${ }^{41}$. El santanderino considera fuera de toda duda la pertenencia de tales versos a la elegía I $2^{42}$ y él, que parece haber seguido también la disposición de los dísticos de la elegía I 1 según la edición de Barbou para esta versión en cuartetos, no los incluye, en consecuencia, en su nueva traducción. Pero lo que sí hace, como decimos, es variar absolutamente el orden de bastantes dísticos de la composición tibuliana en comparación al texto de la edición inglesa de G. Pickering que había seguido en la traducción en tercetos, viniendo a coincidir en este caso con el que muestra la edición que el cántabro señala que Pérez del Camino posiblemente siguiera. Para mayor concreción, el orden de versos adoptado en la traducción en cuartetos de la elegía I 1, conforme a dicha edición francesa y tomando como referencia la edición de Pickering, es el siguiente:

$1,2,3,4,5,6,9,10,7,8,29,30,31,32,35,36,11,12,15,16,13,14$ [en la edición de Barbou el orden es 13, 14, 15, 16], 17, 18, 19, 20, 21-24 [omitidos en la traducción de don Marcelino], 37-40, 33-34, 41-50 [de los que Menéndez Pelayo omite traducir los vv. 49-50], 25-28 [de los que se omiten los vv. 25-26], 51-58 ${ }^{43}$ y 59-78 [en la traducción se omiten los vv. 65-66].

Por lo demás, aparte de la sustanciosa reducción en el número de versos que utiliza para traducir el texto de Tibulo en comparación con la versión en tercetos, la adaptación realizada en cuartetos carece de las mismas bondades que aciertos le faltan a la primera, por más que el erudito se esforzara en limar su traducción aliviando sobre todo la carga amplificadora. Es tan anárquica como aquélla a la hora de seguir una pauta que rija el modo de dar cabida a los dísticos del original: empieza empleando ocho versos para cada tres dísticos, pero hacia la mitad del trabajo esta norma se abandona y da paso a otra tendencia que lleva a reservar un cuarteto completo para cada uno de los dísticos que traduce y que se rompe hacia el final, sin respetarse ya ni la pauta inicial ni esa segunda norma, pues don Marcelino puede ahora extender un solo dístico a lo largo de ocho (así ocurre con los vv. 59-60 de Tibulo en que el poeta vislumbra cómo será su funeral en compañía de Delia, tal como había hecho en la traducción en tercetos) o volcar tres estrofas latinas en sólo seis versos castellanos (así los vv. 69-74 que quedan encerrados en un número equivalente en la traducción).

\footnotetext{
41 «Camino, que siguió las ediciones antiguas, los puso en la elegía primera y, sin embargo, el texto latino que se coloca enfrente de su versión los inserta en la segunda. Al lector que no vaya prevenido, le extrañará, sin duda, esta diferencia, y aun juzgará, si lee sólo la primera, que el intérprete ha hecho en ella impertinentes adiciones» (Menéndez Pelayo 1952-1953, vol.IV, p.56).

${ }^{42}$ «Estos dísticos han sido trasladados por los editores modernos a la elegía segunda, a la cual indisputablemente pertenecen» (Menéndez Pelayo 1952-1953, vol.IV, p.57).

${ }^{43}$ Tras estos versos irían, en la edición de Barbou, los vv. 73-80 y 67-72 (en este orden) de la elegía I 2 que no traduce Menéndez Pelayo.
} 
Sin tanto engrosamiento, pues, de la materia a traducir, la versión de Menéndez Pelayo en cuartetos abraza con más limpieza el sentido literal de la elegía tibuliana y evita algunos puntos oscuros que se apreciaban en la realizada previamente en tercetos. Buena muestra de ese plácido discurrir por el sentido diáfano del texto latino lo podemos encontrar también, sin ir más lejos, en la traducción que de los vv. 61-64:

Flebis et arsuro positum me, Delia, lecto, tristibus et lacrimis oscula mixta dabis.

Flebis: non tua sunt duro praecordia ferro vincta, neque in tenero stat tibi corde sílex,

se plasma en este preciso y aquilatado cuarteto:

Tú llorarás sobre la alzada pira,

Triste beso a las lágrimas mezclando;

Que no es de pedernal tu pecho blando,

Ni tus entrañas como férrea vira,

o también podemos apreciarlo en el comedido circunloquio que le lleva a versionar la mención a Priapo y su deformidad que leemos en los vv. 17-18:

Pomosisque ruber custos ponatur in hortis, terreat ut saeva falce, Priapus, aves,

en otra estrofa que abarca por completo el cuarteto todo para no pisar, acaso, la línea roja de la impudicia por mor de la concisión a que le hubiera forzado el hacerlo en tan sólo un par de versos:

Y en los huertos pomíferos, inmundo,

La diestra armada de segur tajante,

Priapo ahuyentara la grey volante,

Con forma obscena y rostro rubicundo.

Y aunque toda la versión es, por estos motivos, mucho más clara que la primera, hay también algún pasaje que ahora, a fuerza de tanta concreción y labor limae, ha quedado desdibujado en su relación con el texto original. Muy representativo de ello es el caso de la pérdida del parecido literal que tienen con los vv. 57-58 de Tibulo:

Non ego laudari curo: mea Delia, tecum

dum modo sim, quaeso segnis inersque vocer,

aquellos de la traducción que sintetizan el dístico anterior (vv. 55-56) ${ }^{44}$ y éste mismo en el cuarteto que sigue:

${ }^{44}$ I 1, 55-56: Me retinent vinctum formosae vincla puellae, / et sedeo duras ianitor ante fores. 
Mas yo cautivo en tus hermosos ojos, Oh Delia, estoy, y ante tu puerta dura,

Alegre me consumo en vida oscura Por sólo un beso de tus labios rojos,

y en el que puede verse la reticencia del traductor a valorar positivamente el deseo tibuliano por ser iners y segnis de acuerdo a un ideal de amor que don Marcelino no debió de entender en absoluto desde su ambicioso y activo proyecto de vida.

Pero, según decimos, esta nueva versión mantuvo algunos de los que seguramente Menéndez Pelayo consideraba aciertos de la traducción originaria en tercetos. Son varios los endecasílabos rescatados de la primera traducción que, a veces con leves variantes, forman parte de los cuartetos de la segunda, según puede comprobarse por un rápido cotejo de ambas versiones ${ }^{45}$. En algunos casos no sólo se trata de versos sueltos que se han visto salvados de la poda que el escrupuloso rigor del erudito llevó a cabo, sino también de estrofas enteras que, a buen seguro, debían de parecerle ciertamente logradas y que, como es posible ver, se esforzó por amoldar desde el formato del terceto al que le brindaba el ahora elegido del cuarteto. Y aunque esta traducción no es un notable ejemplo de sistematización en su afán por recoger uno o dos dísticos latinos en cada estrofa (como el propio erudito valoraba en la traducción de Pérez del Camino), lo que sí está claro es que la nueva elección le permitió afinar mucho más su primer acercamiento al texto de Tibulo y logró no dejarse nada sin traducir y no abusar en exceso, según se ha dicho, del expediente de la amplificación.

Así ocurre, por ejemplo, con la traducción de los vv. 33-34 que podría estar por méritos propios dentro del cupo ya comentado de casos excepcionales en que cada dístico quedaba recogido en un solo y preciso terceto, esto es, que sería una de las pocas ocasiones en que Menéndez Pelayo consiguió no salirse del pautado que le brindaba la estrofa y pudo encajar en él la práctica totalidad del dístico que traducía. En esta ocasión la traducción que hiciera en la primera versión no dejaba demasiados resquicios para la hinchazón del original, no cabía nada más porque los tres endecasílabos lograban traducir casi ad pedem litterae, y en el formato receptor, la imprecación de Tibulo a lobos y ladrones para que respetaran su mermada grey. De tal forma, a los versos latinos mencionados:

\footnotetext{
45 Además de los casos que vamos a comentar, añádanse los versos siguientes (que citamos según aparecen en la primera versión en tercetos y según lo hacen en la traducción en cuartetos): «Cuando me entregue al piélago inconstante» / «Cuando me entregue al piélago inconstante», «Á tí, oh Mesala, bélica prudencia» / «A ti, oh Mesala, bélica prudencia», «Pertenece mostrar por tierra y mares» / «Pertenece mostrar por tierra y mares», «Mas yo cautivo en los hermosos ojos» / «Mas yo cautivo en tus hermosos ojos», «De Delia estoy, y ante su puerta dura» / «Oh Delia, estoy, y ante tu puerta dura», «Y por ti me consumo en vida oscura» / «Alegre me consume en vida oscura», «No importunes mi sombra; el dolor pasa» / «No importunes mi sombra; el dolor pasa», «No te meses el nítido cabello» / «No te meses el nítido cabello», «No oscurezcas la lumbre que me abrasa» / «No oscurezcas la lumbre que me abrasa», «No maltrates, oh Delia, el rostro bello» / «No maltrates, oh Delia, el rostro bello», «Yo te amaré, pues lo consiente el hado» / «Hoy te amaré, pues lo consiente el hado», «Ya vendrá la vejez con pié callado» / «Ya vendrá la vejez con pie callado», «Cubierta de tinieblas la cabeza» / «Cubierta de tinieblas la cabeza», «Estas mis guerras son y mis dolores» / «Estas mis guerras son y mis dolores», «Yo viviré contento con mis eras» / «Yo viviré contento con mis eras» (aunque ubicado antes del siguiente) y «Despreciador de la pobreza y oro» / «Despreciador de la pobreza y oro» (aunque ubicado después del anterior).
} 
At vos exiguo pecori, furesque lupique,

parcite: de magno est praeda petenda grege,

don Marcelino les hacía corresponder esta versión en tercetos:

¡Oh ladrones! ¡Oh lobos carniceros!

Os ruego perdoneis á mis ganados,

Buscad para la presa otros senderos!,

haciéndoles corresponder también después esta otra en cuartetos:

¡Oh ladrones, oh lobos carniceros,

Os ruego perdoneis a mi ganado;

Otro redil os dé botín colmado,

Buscad para la presa otros senderos!

Lejos de parecer que esta segunda versión amplifica con un endecasílabo añadido (y verosímilmente redundante) la justa traducción de la primera, lo cierto es que su aparición le brinda a Menéndez Pelayo una excelente ocasión para aquilatar con más exactitud su interpretación del texto tibuliano. En efecto, según puede comprobarse, en la adaptación en tercetos, aun reconociendo su completa literalidad, se había quedado sin traducir el sintagma de magno grege que en el pentámetro iba referido a petenda est («buscad para la presa otros senderos»), por más que la idea se insinuara en la adición del término 'senderos', acaso evocador del trashumante deambular de los rebaños y, por ello, de los rebaños mismos. Sin embargo, la versión en cuartetos sí lo recoge bajo la traducción «otro redil os dé botín colmado», que, a pesar de variar en algo la relación de dicho sintagma con los elementos de que depende (de ahí que tenga que introducir un nuevo imperativo semejante al que está implícito en la construcción perifrástica de peto), completa de muy mejor modo - como pensaba don Marcelino que tenían que hacer las traducciones- el sentido global del texto original. Lo que ya no hizo el erudito cántabro fue modificar (de darse por bueno el sentido que hemos asignado al término 'senderos' como receptor de la idea subyacente que hay en de magno grege) la versión primera que, por estar enteramente conservada en esta segunda, tan aceptable le debió de parecer.

Un caso similar de mantenimiento de la primera versión con leves cambios y con introducción de nuevos y más afinados matices, lo encontramos en la traducción de los vv. 59-60 de la elegía tibuliana en que el poeta latino visualiza su última hora en compañía de Delia. La escena, que debió parecerle a don Marcelino, como ya vimos, de una fuerza dramática notable a tenor de la amplificación con que la había volcado en su traducción en tercetos, sigue conservando buena parte de la materia añadida entonces en su adaptación a la nueva versión en cuartetos, aunque ciertamente aligerada (se han suprimido de ella, en concreto, dos endecasílabos) y más precisa en la traducción del estremecedor verso te teneam deficiente manu, según puede comprobarse por la comparación de ambas versiones:

Y cuando llegue á mí la hora postrera,

Véate yo postrada ante mi lecho 
Derramar una lágrima sincera.

Y desahogando el oprimido pecho,

Invocar el auxilio sobrehumano,

Con lamento que hiera el alto techo.

Y llamando á los Dioses, aunque en vano,

Faltándome las fuerzas y el aliento,

Estrecharte, al morir, con débil mano.

Y cuando llegue a mí la hora postrera

Véate yo postrada ante mi lecho,

Con lamento que hiera el alto techo,

Derramar una lágrima sincera.

Y llamando a los dioses, aunque en vano,

Cuando se extinga mi postrer aliento,

¿Que pueda yo en el último momento

Asirme a ti con moribunda mano!

Con todo, esta segunda traducción en cuartetos, aunque no llegara a satisfacer por completo a su autor por los logros conseguidos (ya vimos cómo decía que la conservaba por tenerle cierto cariño), sí consiguió ofrecer una versión mucho más ajustada y fiel, por no ser tan amplificadora, de la elegía de Tibulo que la que había realizado en un primer momento. Sin embargo, ni una ni otra, a nuestro juicio, hicieron rayar alto la pericia de don Marcelino como traductor del elegíaco, pues ni dan mayor aliento al texto latino por más que el erudito lo infle con su lírica facundia-sobre todo en el caso de la traducción en tercetos-, ni acierta ninguna de las dos a dar con una fórmula capaz de recoger ni la esencia ni la globalidad de los dísticos tibulianos. La sinceridad que mostró Caro al espetarle a nuestro polígrafo su franca y negativa opinión de la versión que él leyó (que fue precisamente la más pulida) quizá sea la postura más apropiada para juzgar ecuánimemente la doble empresa que llevó a cabo el santanderino con la poesía del autor de Gabios.

No volvió don Marcelino a traducir nada más de nuestro elegíaco, ni la elegía I 3 prometida ni mucho menos la versión completa de todo el corpus, según el deseo aquel que le manifestara a Rubió cuando iniciaba su imparable carrera hacia la gloria de la Filología Clásica. Es probable que no tuviera tiempo para ello, de tan inmerso como estaba en sus aspiraciones académicas, ni seguramente ganas de hacerlo, aunque de tener que apuntar algunos de los motivos que, de forma más concreta, hicieron desistir al santanderino de tales proyectos y que, cosa más importante, lo alejaron definitivamente de Tibulo, diríamos que fueron de manera muy significativa estos tres: en primer lugar, el no querer contravenir el juicio de su amigo Laverde en materia de moralidad con respecto a poetas como el de Gabios, que, si bien no era un foco de perversión infecciosa, sí mostraba-recuérdense, por ejemplo, las elegías del ciclo de Márato y las continuas referencias al amor adúltero y prohibido que pueblan las elegíasactitudes poco decorosas y nada apetecibles para los gustos morigerados de cierta intelectualidad; en segundo, la fría acogida que el colombiano M.A. Caro dio a la versión de la elegía I 1 que leyera en los Estudios poéticos y que, según se ha dicho, tan desalentado debió de dejar el ánimo de nuestro erudito en su faceta de traductor; y ter- 
cero, el hecho de que se publicara la traducción completa de Tibulo a cargo de Pérez del Camino justo cuando Menéndez Pelayo empezaba a vislumbrar la posibilidad de hacerlo él mismo, versión ésta muy bien valorada por el propio polígrafo y que pudo hacer ver innecesario y poco productivo - habida cuenta del favorable juicio que le merecía- el esfuerzo de emprender una tarea de similares características.

\section{TIBULO EN LAS OBRAS DE CRÍTICA FILOLÓGICA}

No obstante todo lo anterior, el trato habitual y casi cotidiano que don Marcelino tuvo durante tanto tiempo con Tibulo se manifestó también, por pura lógica, en otras parcelas más sesudas y menos íntimas de su trabajo intelectual, ya fuera porque el lento paladeo de su poesía le permitió valorar con mayor sentido crítico otras traducciones realizadas sobre su obra (como podemos comprobar tanto en la Biblioteca de traductores españoles como en la Bibliografia hispano-latina clásica), o ya porque su amplio conocimiento de nuestra literatura le ayudara a establecer con facilidad vínculos de unión entre la poesía del de Gabios y la de los poetas patrios que tanto frecuentaba (como se plasma en la propia Bibliografía hispano-latina mencionada).

Con respecto a la atención concedida al poeta latino por parte de nuestros traductores, don Marcelino ya constataba una realidad que no han hecho sino confirmar las investigaciones posteriores de quienes se han dedicado a profundizar en la misma cuestión ${ }^{46}$ : que es paupérrima la relación de versiones de Tibulo en nuestras letras y que, salvo la de Pérez del Camino y la inédita o perdida -todavía hoy-del jesuita Ceris y Gelabert (las únicas completas que pudo llegar a conocer don Marcelino), todas eran parciales $y$, en algunos casos, excesivamente parafrásticas ${ }^{47}$. La lista, pues, de todos estos traductores ocasionales y puntuales del elegíaco no ha cambiado mucho desde que quedara más o menos establecida por nuestro erudito gracias a las noticias que de ellas ofrece en la Biblioteca de traductores y en la Bibliografía hispano-latina clásica, excepción hecha de las aparecidas con posterioridad a la muerte de Menéndez

\footnotetext{
${ }^{46}$ Fundamentalmente Fca. Moya del Baño, quien, aparte de haber dedicado a lo largo de varios años importantes trabajos de referencia sobre estos particulares de Tibulo (especialmente Moya [1982] y Moya [1985]), en fecha reciente ha publicado una síntesis completa de la recepción del poeta latino en el ámbito de la traducción (Moya 2009). Tan sólo habría que añadir, más por su singularidad que por otra cosa, la existencia de dos traducciones parciales más de Tibulo: la que A. Miralles Carlo publicó a principios del siglo XX («Tibulo: traducción de algunos poemas», Revista de Libros, Madrid, Editorial Calleja, 1919) y la que el poeta salmantino Aníbal Núñez hizo de la elegía I 6 y publicó en 1987 (Un ángel más, nº 1).

${ }^{47}$ Menéndez Pelayo (1952-1953, vol.IV, p.51): «En diferentes artículos de este Ensayo hemos citado las versiones de Tibulo, que hasta ahora existen en castellano. Breve es por cierto la enumeración. No tenemos noticia de ningún trabajo completo, exceptuando el del jesuíta Ceris y Gelabert, que, o se ha perdido o permanece inédito, sin que hasta ahora hayamos podido averiguar su paradero. Tampoco son numerosas las traducciones sueltas de diversas composiciones. La elegía tercera del libro segundo fué parafraseada por Fr. Luis de León y por Villegas; la segunda del libro primero fué traducida por nuestro terenciano Bretón de los Herreros, cuya reciente pérdida lloran las musas cómicas; y, por último, el autor de esta bibliografía, aunque indigno de entrar en cuenta con tan señalados varones, probó sus fuerzas en esta empresa, traduciendo en tercetos la primera del mismo libro, como muestra, siquiera débil, de su admiración a Tibulo».
} 
Pelayo -ocurrida en 1912- que, obviamente, como decimos, él no tuvo ocasión de conocer. Dicha lista incluye a los siguientes autores que, con mayor o menor detalle, son comentados en las obras de referencia: Fray Luis de León, Esteban Manuel de Villegas, José Cadalso, José Marchena, Manuel Bretón de los Herreros, el ya citado Pérez del Camino, el propio Menéndez Pelayo (como autor de las traducciones o, mejor dicho, de la traducción - pues sólo se da a conocer la versión en cuartetos- de la elegía que hemos visto), Tomás Forteza y Ricardo Catarineu ${ }^{48}$.

Los juicios críticos de Menéndez Pelayo que acompañan a este ramillete de versiones van desde la telegráfica noticia que da fe de su existencia hasta el comentario más elaborado y de cierto calado y extensión. Breve espacio dedicó, por ejemplo, a glosar la traducción que Fray Luis realizó de los vv. 1-34 (con la omisión de los vv. 15-16) de la elegía II 3 de Tibulo, pero, en este caso, la opinión que le merecía suplía cualquier otro comentario más jugoso sobre un autor, el poeta conquense, con tantos puntos en común con el santanderino -así el compartido afecto por Horacio- y sobre una versión que suponía, como la obra toda del belmonteño, un acicate y un modelo para la vida intelectual y moral de nuestro polígrafo ${ }^{49}$. De ella dice con no poca condescendencia: «Peca de difusa esta traducción, como lo notó ya Pérez del Camino, que la trasladó muy concisamente, pero es fácil y agradable» ${ }^{50}$.

Breve es también el comentario que acompaña a la noticia de la versión que Esteban Manuel de Villegas (1589-1669) hizo de la misma elegía que había recreado Fray Luis, la II 3 (aunque ahora él traduzca los vv. 1-24 y 35-36), y que el poeta de Nájera incluyó en sus Eróticas publicadas en $1618^{51}$ : un «notable por su naturalidad y gracia» (Menéndez Pelayo (1952-1953, vol.IV, p.374) es el juicio estimativo que le merece a nuestro erudito un texto como éste de Villegas que el najerense engastó entre una variedad muy significativa de composiciones originales y recreaciones o traducciones parafrásticas - como de hecho es ésta de Tibulo- de otros varios poetas antiguos (Anacreonte, Virgilio, Horacio, etc.).

Nada dice don Marcelino al citar la puntualísima traducción que José Cadalso (1741-1782) hizo de los vv. 19-27 de la elegía II 6 y que aprovechó para ilustrar al-

\footnotetext{
${ }^{48}$ Aunque suele citarse como traductor ocasional de Tibulo en los trabajos que se hacen cuestión de este particular (cf. Moya 1982, p.28), el nombre de Pedro José Pidal, que versionó la elegía I 1, no aparece citado por Menéndez Pelayo ni en la Biblioteca de traductores ni en la Bibliografía hispano-latina clásica. A él se refiere en una carta enviada a Laverde el 4 de octubre de 1876 ( $c f$. Menéndez Pelayo [1982-1991], vol.II, carta 87) donde indica que ha visto, entre las poesías inéditas de Pidal, traducciones de dos odas de Horacio, de una elegía de Tibulo y de una 'anacreóntica' de Catulo (de que la que sí da noticia, por otro lado, tratándose del poema 3 sobre la muerte del pajarillo de Lesbia, en el capítulo dedicado al veronés de la Bibliografía hispano-latina). Indicaciones algo más concretas sobre la versión tibuliana de Pidal pueden verse en Menéndez Pelayo (1877, p.711).

${ }^{49}$ Sobre las afinidades de Menéndez Pelayo con Fray Luis, véase lo señalado por S. de la Nuez (1962, pp.120-121), quien afirma con rotundidad que «para Menéndez Pelayo, Fray Luis era la meta de toda nuestra poesía lírica, porque reunía eso que él andaba buscando siempre: la forma clásica y la simplicidad cristiana que originan el espíritu nuevo» (p.121).

${ }^{50}$ Cf. Menéndez Pelayo (1952-1953, vol.II, p.311). Mucha más atención, de acuerdo también al criterio seguido por Fray Luis para traducir a los autores antiguos, se presta a esta traducción en Schwartz (1992).

${ }^{51}$ Sobre la relación de la traducción de Villegas con el texto tibuliano a la luz de la versión anterior de Fray Luis, véase Arcaz (2012).
} 
gunos de los consejos destinados a los que «pretenden saber mucho estudiando poco» que conforman sus conocidos Eruditos a la violeta, obra publicada en 1772. El silencio es, en este caso, indicativo del poco interés que le despertaba una traducción que, por otro lado, estaba bastante lograda:

En el referido Suplemento inserta, además, traducidos, ligerísimos trozos de Tibulo, Propercio y Ovidio, algunos versos de Boileau y tal cual retacito de menos monta, como ilustraciones a su lección de Poética en Los Eruditos. No merecen el que se haga especial registro de ellos en este lugar (Menéndez Pelayo 1952-1953, vol.I, p.266).

Y menos dice aún de la versión en octosílabos que Manuel Bretón de los Herreros (1796-1873) hizo de la elegía I 2 y publicó en la edición de sus Poesías de $1831^{52}$; tan sólo señala en la Biblioteca de traductores la existencia de la traducción realizada por el riojano («la segunda del libro primero fué traducida por nuestro terenciano Bretón de los Herreros, cuya reciente pérdida lloran las musas cómicas» [Menéndez Pelayo 1952-1953, vol.IV, p.51]), pero ni lo incluye entre los autores analizados ni tampoco lo registra como tal en la Bibliografía hispano-latina clásica.

Todo lo relativo al interés como traductor de Tibulo que José Marchena (17681821) llevó a cabo a lo largo de su ajetreada vida y que don Marcelino había reseñado tanto en la Biblioteca de traductores como en la Historia de los heterodoxos españoles, vino a formar parte del estudio preliminar con que Menéndez Pelayo abrió la edición de las obras completas del conocido abate publicadas en Sevilla en 1892$1896^{53}$. Las antipatías personales e ideológicas que el cántabro tenía por el poeta de Utrera no condicionaron en absoluto el valor que nuestro polígrafo otorgó a los loables esfuerzos de Marchena en su faceta de traductor, aunque no se resistiera a resaltar la vulgaridad y tosquedad que no dejaba de ver en ninguna de las acciones u obras del abate ${ }^{54}$. Así, con gran menosprecio por su obra lírica personal, ciertamente algo desmayada y en exceso dependiente del magisterio neoclasicista de poetas como Meléndez Valdés ${ }^{55}$, el santanderino no tuvo el menor reparo en asegurar en las páginas introductorias de su edición:

Como Marchena, a pesar de su entusiasmo erótico, no tenía ni calor de afectos ni viveza de fantasía, pero sí muchas humanidades y familiar trato con los clásicos, resulta mucho más aventajado poeta cuando traduce o imita que cuando expresa por cuenta propia sus versátiles enamoramientos. Por eso los mejores trozos de esta primera época suya están en sus traducciones de algunas elegías de Tibulo y de Ovidio, las cuales, a parte

\footnotetext{
${ }^{52}$ Véase el análisis de esta traducción de Bretón de los Herreros y de las realizadas por José Marchena en Arcaz (2013a).

${ }^{53}$ Cf. M. Menéndez Pelayo (1892-1896).

${ }^{54}$ Con todo, como es sabido, Menéndez Pelayo procedió a traducir el fragmento de Catulo que Marchena intentó hacer pasar por original sirviéndose del mismo procedimiento que cuatro años antes y con idéntico fin había empleado con un fragmento del Satiricón de Petronio. La traducción del Fragmentum Catulli (publicada por Marchena en París en 1806) se recogió también en los Estudios poéticos. Sobre los textos falsificados del abate véase Manchón (2006) y Álvarez Barrientos (2012).

55 Sobre la factura de la poesía personal de Marchena y su relación con los poetas latinos que tradujo (especialmente Tibulo, Virgilio, Horacio y Ovidio, aparte de Lucrecio), véase Arcaz (2013b).
} 
[sic] de cierta bronquedad y dureza de estilo de que no pudo librarse nunca Marchena ni en verso ni en prosa, y que contrastan con la blanda manera de los poetas a quienes interpretaba, demuestran, por lo demás, un estudio nada vulgar ni somero de la lengua poética castellana, y se recomiendan por un agradable dejo arcaico.

No obstante, con anterioridad a la publicación de la obra literaria de Marchena, don Marcelino ya había hecho notar, mas a través de un escueto comentario, la pericia del abate en la ejecución de su versión de la elegía II 1 de Tibulo, de la que en la Biblioteca de traductores sólo recoge parte del texto que el propio poeta de Utrera publicó en sus Lecciones de filosofía moral y elocuencia (obra publicada en Burdeos en $1820)^{56}$, aunque luego la incluyera completa - tras darla a conocer en la edición de las obras literarias de Marchena- en la Bibliografía hispano-latina clásica. Dice nuestro polígrafo sobre el fragmento recogido en la primera de las obras en que se cita la traducción que «tiene fidelidad y color poético, pero la versificación es trabajosa, y el estilo poco suelto» (Menéndez Pelayo 1952-1953, vol.III, p.18) y que no resiste comparación alguna con la que de la misma elegía hizo, cómo no, su admirado Pérez del Camino ${ }^{57}$. Además de esta versión de la lustración campestre del poema que abre el libro II de Tibulo, don Marcelino recoge en la Bibliografia hispano-latina, también con toda ausencia de comentario añadido, la traducción que Marchena hiciera de la elegía I 2.

Por lo que llevamos dicho a propósito de las anotaciones que acompañan las noticias de traducciones y traductores de Tibulo que pergeñó don Marcelino, es fácil imaginar que el comentario más granado que leemos al respecto en la Biblioteca de traductores se corresponde con el que iba a dedicar a la ya tantas veces citada versión que Pérez del Camino publicó en 1874. Aunque Menéndez Pelayo accedió con prontitud a la obra una vez publicada (recuérdese que la había recibido de manos del propio Alonso Martínez en torno a septiembre de 1874 y que su noticia crítica está datada el día 19 de marzo de 1875), hay que indicar que dicha versión se había acabado, al menos, casi sesenta años antes de ver la luz, concretamente en 1815, como consta en la fecha que rubrica el prólogo que redactó Manuel Alonso Martínez, sobrino del traductor. Menéndez Pelayo, según ya hemos dicho, valoró de forma extremadamente favorable el admirable empeño del burgalés, hasta el punto de considerar que esta traducción era «digna de entrar en cuenta con las mejores que de poetas latinos existen en nuestra lengua, con la Tebaida de Juan de Arjona con el Horacio de Burgos, con el libro primero de la Eneida de Ventura de la Vega con los bucólicos y algún otro trabajo de D. Juan Gualberto González y con el Pervigilium Veneris que parafraseó D. Juan Valera» (Menéndez Pelayo 1952-1953, vol.IV, p.56).

De la traducción de Pérez del Camino nuestro polígrafo valora con entusiasmo casi todo: la introducción (de la que describe su contenido y los aspectos que toca),

\footnotetext{
${ }^{56}$ Sin embargo, la traducción completa fue publicada con anterioridad, concretamente en 1807 , en el Correo de Sevilla con las iniciales J.M.

${ }^{57}$ Menéndez Pelayo (1952-1953, vol.III, p.19): «Compárese este retazo, bueno, pero laborioso, con la brillantísima, animada e incomparable traducción que de esta elegía hizo Pérez del Camino, y se verá la diferencia».
} 
la variada elección de los metros utilizados en ella (con reseña significativa de la facultad del burgalés -que no practicó don Marcelino en sus versiones, como hemos visto- para traducir en igual número de versos algunas elegías de Tibulo) y la elegancia y concisión con que afronta la adaptación del pensamiento del autor latino hasta lograr infundir a sus endecasílabos la misma sensación de serena belleza que, dice nuestro erudito, poseen los versos del de Gabios ${ }^{58}$.

El panorama que hemos reseñado, y que se describe fundamentalmente en la $\mathrm{Bi}$ blioteca de traductores, se completa con casi las mismas noticias aportadas en la $\mathrm{Bi}$ bliografía hispano-latina, aunque en ella se incluyen, como hemos dicho, nombres y textos que no habían sido ni mencionados antes, debido, en justa lógica, a que son referencias que conoció con posterioridad a la redacción de la primera obra. Con respecto a lo ya dicho, hay que añadir a la lista de traductores ocasionales de Tibulo, entre otras versiones de menor entidad y que apenas merecen la atención del santanderino $^{59}$, los nombres de Tomás Forteza y de Ricardo Catarineu, aunque nada más sustancioso que la mera inclusión de la traducción correspondiente se diga de ellos en la Bibliografía hispano-latina clásica.

Del primero se recoge una traducción de la elegía I 3 realizada en cuartetas formadas por tres endecasílabos y un heptasílabo, y, a pesar de la ausencia de datos más concretos sobre la versión, gracias a la correspondencia epistolar de don Marcelino podemos saber no sólo el modo en que el texto llegó a sus manos, sino también la opinión -escueta, eso sí- que le merecía el trabajo realizado por su traductor. Tomás Forteza (1838-1898) fue un poeta y filólogo mallorquín que gracias a la influencia de Menéndez Pelayo, y a petición de Mariano Aguiló (activo catalanista amigo del cántabro y maestro del primero), llegó a ser Secretario de la Junta Provincial de Instrucción Pública de Palma de Mallorca, ciudad por la que nuestro erudito fue elegido diputado en 1884. La mediación del santanderino en la consecución de esa plaza le granjeó el eterno reconocimiento de Forteza, quien no dejó pasar ninguna de las oportunidades que le brindaba el poder cartearse con don Marcelino para expresarle a su mentor su mucho más que sincero agradecimiento. Antes de ocupar ese cargo, el mallorquín había sido profesor de latines en diversas instituciones privadas, lo que explica su excelente competencia no sólo para traducir con sumo equilibrio y templanza la elegía de Tibulo, sino también para escribir, si fuera el caso, dísticos latinos en loor de la Virgen de Lluch $^{60}$. La traducción que nos ocupa le fue remitida a Menéndez Pelayo por Antonio Rubió - que dice haberla encontrado entre sus papeles- en una carta fechada el 2 de mayo de 1890. No consta que don Marcelino la recibiera con demasiado entusiasmo, pero sí que agradeciera a su amigo el envío haciéndole saber la recepción de «la elegante traducción de Tibulo hecha por Tomás Forteza».

\footnotetext{
${ }^{58}$ Menéndez Pelayo (1952-1953, vol.IV, pp.53-54): «Nunca es difícil ni premioso, nunca, o pocas veces, resulta oscuro el concepto, antes suele ganar en belleza, acercándose, en lo que cabe, a la purísima forma clásica del original, modelo de sencillez y de no afectada elegancia».

${ }^{59}$ Asi, por ejemplo, las de Bernaldo de Balbuena y Félix María Hidalgo.

${ }^{60}$ Dísticos que le llegó a enviar a Menéndez Pelayo en una carta fechada el día 3 de julio de 1884, al poco tiempo de haber obtenido la vacante de Secretario para la que Aguiló le pidió la recomendación a nuestro polígrafo.
} 
En el caso del segundo de los traductores incluidos en la Bibliografía hispanolatina clásica tenemos aún menos información. Ricardo Catarineu (1868-1915), también conocido como Caramanchel, fue un poeta de cierto éxito en los círculos de la bohemia madrileña de finales del siglo XIX y un activo crítico teatral que ejerció su labor preferentemente en el diario La Correspondencia de España. Fue aquí donde publicó, el día 5 de abril de 1903, la traducción que, con gran tino y en endecasílabos libres, hizo de la elegía I 10 que Menéndez Pelayo recoge en su compilación y sobre la que no expresa opinión ni comentario alguno.

Por otro lado, las aportaciones que hizo don Marcelino al conocimiento de la presencia literaria de Tibulo en nuestras letras son poco significativas, pero no porque fuera éste un ámbito que hubiera descuidado nuestro polígrafo, sino sobre todo porque las huellas del poeta latino en la literatura española son, en efecto, escasas, aunque no tanto como pudiera parecerle a quien sólo tuviera en cuenta la menguada listada (integrada por Juan de la Cueva, Nicolás Fernández de Moratín y Andrés Bello) que incluye en el apartado de imitaciones y reminiscencias ${ }^{61}$.

No desaprovechó tampoco Menéndez Pelayo su conocimiento de Tibulo para ilustrar algunas de las cuestiones tratadas en su laboriosa Historia de los heterodoxos españoles, obra que publicó entre 1880 y 1882. En el capítulo dedicado al análisis de las prácticas supersticiosas durante los períodos romano y visigodo, inserto en el primero de los volúmenes de los cuatro de que consta la obra, habla de la execración que le merecían tales costumbres en la antigüedad y refiere, entre otras mucho más menudas alusiones, algunas de las que aparecen en los poemas tibulianos, sacándolas del contexto en que se encuentran y sin valorar los condicionantes del género al que pertenecen y las justifican como un motivo literario más de la elegía. Don Marcelino, pues, sin entrar en mayores consideraciones, se limita a señalar los poderes mágicos que el poeta latino atribuye a la hechicera que en la elegía I 2 podía procurarle al de Gabios el amor de su puella (especialmente en los vv. 53-54 que cita), a los conjuros puestos en práctica por Tibulo para aliviar la enfermedad de Delia que se recogen en I 5, 914 y a las sortes de las que su amada se informó, según se especifica en I 3, 11-12, para asegurarse el regreso del viaje que el poeta latino describe en esta elegía y que tan malos presagios le inspirara antes de acometerlo (Menéndez Pelayo 1948, pp.390391). Y en todos los casos, como no podía ser menos, los textos tibulianos que se citan proceden de la traducción de Pérez del Camino que tanto gustaba al erudito.

A pesar de todas estas referencias que muestran la natural sintonía que Menéndez Pelayo manifestó a lo largo de toda su vida científica con la poesía tibuliana, la historia de esa relación tan especial que nuestro polígrafo mantuvo con el poeta terminó realmente con la publicación en 1878 de la versión en cuartetos de la elegía I 1; nada de lo prometido cuando le asaltaba el entusiasmo juvenil del filólogo en ciernes que entonces era don Marcelino se pudo materializar con el correr de los años: abandonó su determinación de traducir, además de la I 1, la elegía I 3 y, lo más importante de todo, la intención de volcar por vez primera al castellano todos los poemas del corpus. Como hemos dicho, la

\footnotetext{
${ }^{61}$ Más datos, desde luego, de la recepción literaria de Tibulo en nuestras letras pueden encontrarse en la valoración sumaria que se hace en Moya (1982, pp.23-25). Véase también Tibulo (1994, pp.40-44).
} 
actitud antipagana y censora de su amigo Laverde, así como la constatación de que para traducir a Tibulo hacía falta algo más que buenas intenciones (como le vino a sugerir M.A. Caro al santanderino), pudieron acaso entibiar la querencia del cántabro por nuestro autor, llevándolo paulatinamente a aficionarse por otros poetas y textos clásicos -así los de Horacio- más cercanos, por afinidad ideológica y sentimental, al talante de nuestro erudito. Lo mismo ocurrió con sus anhelos de poeta, que se vieron igualmente truncados con el devenir del tiempo y el abandono de aquellas sus primeras fuentes de inspiración. Pero, en cualquier caso, fue mucho el provecho que nuestro erudito sacó del pequeño ejemplar regalado por Posada y mucha la ciencia que empezó por aquel entonces a gestarse: a ella contribuyó también la simpatía adolescente de un Menéndez Pelayo enamorado, como joven que era, de la vida y de los versos de amor de Tibulo.

\section{REFERENCIAS BIBLIOGRÁFICAS}

Alas “Clarín”, L. (1887), «Poesía de Menéndez Pelayo», Nueva Campaña (1885-1886), Madrid, Fernando Fe, pp.159-170.

Álvarez Barrientos, J. (2012), «Erótica y erudición: la fuerza de lo falso en el Fragmentum Petronii de José Marchena», en Martínez, J. (ed.), Mundus vult decipi: estudios interdisciplinares sobre falsificación textual y literaria, Madrid, Ediciones Clásicas, pp.37-46.

ArCAz Pozo, J.L. (2012), «La elegía II 3 de Tibulo en las versiones de fray Luis de León y Esteban Manuel de Villegas», en Del latín a las lenguas romances: lengua entre culturas, cultura entre lenguas. Actas del VII Congreso de la Sociedad de Estudios Latinos (Toledo, 13-16 de junio de 2012), en prensa.

Arcaz Pozo, J.L. (2013a), «Las traducciones tibulianas de José Marchena y Manuel Bretón de los Herreros», Analecta Malacitana Electrónica 34 (2013), pp.65-85.

Arcaz Pozo, J.L. (2013b), «Los poetas latinos en la poesía personal de José Marchena (1768-1821)», en Beltrán, J.A. - Encuentra, A. - Fontana, G. - Magallón, A.I. - MaRINA, R.M (eds.), Otium cum dignitate. Estudios en homenaje al Prof. J.J. Iso Echegoyen, Zaragoza, Universidad de Zaragoza, pp.369-380.

Barrera, J. (1909), «El joven traductor de Tibulo M. Menéndez Pelayo», La Cataluña 4 de septiembre, pp.542-543.

Bravo Vega, J. (1998), «La poesía de Valera y Menéndez Pelayo», en Historia de la literatura española. Tomo 9. Siglo XIX (II), Madrid, Espasa Calpe, pp.213-222.

Bueno SÁnchez, G. (1990), «Gumersindo Laverde y la Historia de la Filosofía Española», El Basilisco 5, pp.49-85.

Carballo Picazo, A. (1956), «Laverde y Menéndez Pelayo», Revista de Literatura 9, pp.19-38.

CAstro de CAstro, J.D. (2005), «Las versiones de poesía épica latina en el s. XIX», en GARCÍA JuRAdo, F. (comp.), La historia de la literatura greco-latina en el siglo XIX español: espacio social y literario, Málaga, Anejo LI de Analecta Malacitana, Servicio de Publicaciones de la Universidad de Málaga, pp.205-226.

Nuez Caballero, S. De la (1961), «Sondeos críticos en las poesías de Menéndez Pelayo», Anales de la Universidad de Murcia 20.3-4, pp.111-138.

Diego, G. (1931), «Menéndez Pelayo y la historia de la poesía española hasta el siglo XIX», Boletín de la Biblioteca Menéndez Pelayo 13, pp.115-139. 
Eguía Ruiz, C. (1917), «Menéndez Pelayo considerado como poeta», en Literatura y literatos. Autores contemporáneos (1914-1917), Madrid, Sáinz de Jubera, pp.205-228.

GonZÁlez GonzÁlez, M. (2003), «Versiones decimonónicas en castellano de la Oda a Afrodita (Frg. 1 Voigt) y de la Oda a una mujer amada (Frg. 31 Voigt) de Safo», Cuadernos de Filología Clásica (Estudios Griegos e Indoeuropeos) 13, pp.273-312.

GonzÁlez GonzÁlez, M.-GonzÁlez Delgado, R. (2005), «La lírica griega: Safo, Anacreonte, Tirteo y Bucólicos», en García Jurado, F. (comp.), La historia de la literatura grecolatina en el siglo XIX español: espacio social y literario, Málaga, Anejo LI de Analecta Malacitana, Servicio de Publicaciones de la Universidad de Málaga, pp.181-204.

Hernández Vista, E. (1956), El mundo clásico visto por Menéndez Pelayo, Madrid, Editora Nacional.

Laín Entralgo, P. (1963), «Menéndez Pelayo y el mundo clásico», Cuadernos de la Fundación Pastor 7, pp.11-38.

Lasso de La Vega, J.S. (1958), «Menéndez Pelayo y la Filología Clásica en España», en Actas del I Congreso Español de Estudios Clásicos (15-19 de abril de 1956), Madrid, Sociedad Española de Estudios Clásicos, pp.1-33.

MANCHÓN GómEZ, R. (2006), «El abate de Marchena, traductor y escritor latino (Pseudo-Petronius, Pseudo-Catullus)», en Miguel Jover, J.L. DE - JimÉnez Serrano, A. (eds.), Maestro y sabio. Didáskalos kai sophós: homenaje al profesor Juan Jiménez Fernández, Jaén, Servicio de Publicaciones de la Universidad de Jaén, pp.65-106.

Martín Puente, C. (2010), «Marcelino Menéndez Pelayo y los estudios clásicos», en GARCíA JuRAdo, F. (ed.), La historia de la literatura grecolatina durante la Edad de Plata de la cultura española (1868-1936), Málaga, Anejo LXXVIII de Analecta Malacitana, Servicio de Publicaciones de la Universidad de Málaga, pp.239-267.

Menéndez Pelayo, E. (1922), Memorias de uno a quien no sucedió nada, Madrid, Editorial Voluntad.

MenÉndez Pelayo, M. (1877), «Traductores castellanos de Horacio», Revista Europea 172, pp. 709-745.

MenÉNDeZ Pelayo, M. (1878), Estudios poéticos, prólogo de Leopoldo Augusto de Cueto, Madrid, Imprenta Central.

Menéndez Pelayo, M. (1883), Odas, epístolas y tragedias, prólogo de Juan Valera, Madrid, Imprenta de A. Pérez Dubrull.

MenÉndez Pelayo, M. (1892-1896), Obras literarias de D. José Marchena, recogidas de manuscritos y raros impresos, Sevilla, Imprenta de Rasco, 2 vols.

Menéndez Pelayo, M. (1948), Historia de los heterodoxos españoles, Madrid, Santander, Consejo Superior de Investigaciones Científicas, vol. I.

Menéndez Pelayo, M. (1982-1991), Epistolario, edición al cuidado de M. Revuelta Sañudo, Madrid, Fundación Universitaria Española, 22 vols.

Moya del Baño, FCA. (1982), Presencia de Tibulo, Murcia, Servicio de Publicaciones de la Universidad de Murcia.

MoYA DEL BAÑo, F. (1985), «Notas sobre ediciones y comentarios sobre Tibulo desde el humanismo», en Simposio Tibuliano. Conmemoración del Bimilenario de la muerte de Tibulo, Murcia, Servicio de Publicaciones de la Universidad de Murcia, pp. 59-87.

Moya del Baño, F. (2009), «Tibulo», en Lafarga, F. - Pegenaute, L. (eds.), Diccionario histórico de la traducción en España, Madrid, Gredos, pp.1096-1098. 
Oroz, R. (1956), «Don Marcelino Menéndez Pelayo y la poesía latina», Anales de la Universidad de Chile 114, pp.7-25.

Pabón, J.M. (1957), Menéndez Pelayo y la poesía clásica, Madrid, Universidad de Madrid.

SÁnchez ReYes, E. (1974), Biografía crítica y documental de Marcelino Menéndez Pelayo, Madrid, Consejo Superior de Investigaciones Científicas.

Schwartz, L. (1992), «Fray Luis y las traducciones de los clásicos: la elegía II,iii de Tibulo», Edad de Oro 11,175-186.

TiBulo (1721), Corpus omnium veterum poetarum latinorum, tam prophanorum quam ecclesiasticorum, cum eorum, quotquot reperiuntur, fragmentis, tomus I, Londini, Prostant vero Hagae Comitum, apud Isaacum Vaillant.

Tibulo (1743), Catullus, Tibullus, Propertius \& ad optima exemplaria emendati, cum fragmentis Cornelio Gallo inscripta, Parisiis, typis J. Barbou, via San-Jacobea.

Tibulo (1824), Catullus, Tibullus et Propertius, Londini, impensis G. Pickering, 57 Chancery Lane.

Tibulo (1829), Catullus, Tibullus, Propertius, editio stereotypa ex nova tabularum impressione emendatissima Lipsiae suntibus et typis Caroli Tauchnitii.

Tibulo (1874), Elegías de Tibulo, traducidas al castellano por D. Norberto Pérez del Camino, con un prólogo del Excmo. Sr. D. Manuel Alonso Martínez, Madrid, Imprenta de Julián Peña.

Tibulo (1994), Tibulo. Elegías, introducción, traducción y notas de J.L. Arcaz Pozo, Madrid, Alianza Editorial. 


\section{APÉNDICE}

La traducción de la elegía I 1 en tercetos a partir de la edición londinense de G. Pickering (1824)

Junte otro las riquezas y el tesoro,

Mil yugadas de suelo cultivado;

Duerma feliz sobre montones de oro.

Y su tranquilo sueño sea turbado

Por el bélico son de los clarines,

Y del lecho levántese azorado.

Vea asaltar de su heredad los fines,

Y las armas del bárbaro enemigo

Talen á sangre y fuego sus confines.

Sufra de sus riquezas el castigo,

Yo no escucho el sonido de la trompa,

$\mathrm{Y}$ en la pobreza ser feliz consigo.

Porque no anhelo el fausto ni la pompa,

Miéntras brille en mi hogar continuo fuego,

Ni nada quiero que mi sueño rompa.

Ni de honores en pós andaré ciego;

Maduras frutas cogerá mi mano,

$\mathrm{Y}$ tiernas vides plantaré yo luégo

En la ladera, y en el verde llano;

$\mathrm{Y}$ al ver las mieses y el ardiente vino,

La Esperanza, consuelo del humano,

No dejará mis puertas, pues divino

Veneraré su nombre en los altares

$\mathrm{Y}$ en las antiguas piedras del camino.

$\mathrm{Y}$ al ver llenos de mosto mis lagares,

Ofreceré los frutos del verano

Al Dios Pan, que protege mis hogares.

Florida espiga cogerá mi mano,

Dorada Céres, para tu corona,

Que en rico templo penderá romano.

Léjos de mí las armas de Belona,

Á Príapo alzaré estátua y altares

En los fértiles campos de Pomona

Y á vosotros tambien, divinos Lares,

Que el campo protegeis, feliz un día,

Que velais por mis rústicos hogares.

Entonces una vaca yo ofrecía,

Y becerros sin número lustraba,

Una cordera es hoy la ofrenda mía.

Y si entónces un buey sacrificaba,

Al inmolaros hoy pobre cordero,

La campesina juventud gritaba: 
«Dádnos, oh Dioses, con propicio agüero,

Granadas mieses y abundante vino».

Vivir contento en la pobreza quiero.

Á la sombra de un árbol me reclino,

Recostado á la márgen de una fuente,

Evito los ardores del camino.

Y al murmurar la plácida corriente,

Al deslizarse en la menuda arena,

Mi triste corazon placeres siente.

Y si el balido de la oveja suena,

Ó hiere el aguijon los tardos bueyes,

Ó el cabritillo por su madre pena;

Vuelvo la oveja á sus perdidas greyes

Ó miro cómo pacen mis corderos,

Y no envidio la suerte de los reyes.

¡Oh ladrones! ¡Oh lobos carniceros!

Os ruego perdoneis á mis ganados,

Buscad para la presa otros senderos!

En esta fuente, pues, somos lustrados

Mis pastores y yo todos los años

$\mathrm{Y}$ los dones á Palas consagrados.

¡Oh Dioses! apartad todos los daños,

No desprecieis los dones ofrecidos

Con pura voluntad y sin engaños!

Aunque de pobre mesa recogidos,

Para ornar de los Dioses los altares,

$\mathrm{Y}$ en vasijas de barro contenidos.

Antiguo labrador, en sus hogares,

De barro fabricó rústicos vasos,

Para hacer libaciones á sus Lares.

No de mis padres (por diversos casos

Perdidas) las riquezas ambiciono,

Que el tiempo se llevó con largos pasos.

No me deslumbra el esplendor de un trono;

Con pequeña heredad vivo contento,

Los paternos tesoros abandono.

Dulce es oir el animoso viento,

Escuchar desde el lecho en que reposo

Del Aquilon el ímpetu violento!

$\mathrm{Y}$ cuando en el invierno el Austro acuoso

Cubre de hielo el campo y el repecho,

El blando sueño es grato y deleitoso.

Dulce es dormir en el tranquilo lecho,

Y al compás de la lluvia que desciende,

Entrechar á mi amada sobre el pecho.

Esto tan solo mi ambicion pretende;

Quien sufre de la lluvia los rigores

Y sobre el ancho mar las velas tiende; 
Quien arrostra los bélicos furores, Este solo alcanzar puede riqueza, Á precio de fatigas y dolores.

Perezca el oro, plata, y la belleza

De la verde esmeralda y el diamante,

Que aumentan esplendor á la grandeza.

Antes que el pecho de mi tierna amante,

Suspire y llore por mi triste ausencia,

Cuando me entregue al piélago inconstante.

Á tí, oh Mesala, bélica prudencia

Pertenece mostrar por tierra y mares,

Y de la guerra ejercitar la ciencia.

En triunfo volverás á tus hogares,

Suspendiendo á tus puertas los despojos,

Que la guerra te dió con sus azares.

Mas yo cautivo en los hermosos ojos

De Delia estoy, y ante su puerta dura

Sufro de amor la pena y los enojos.

Tú eres, oh Delia, toda mi ventura,

No ambiciono la fama lisongera,

Y por tí me consumo en vida oscura.

Y cuando llegue á mí la hora postrera,

Véate yo postrada ante mi lecho

Derramar una lágrima sincera.

Y desahogando el oprimido pecho,

Invocar el auxilio sobrehumano,

Con lamento que hiera el alto techo.

Y llamando á los Dioses, aunque en vano,

Faltándome las fuerzas y el aliento,

Estrecharte, al morir, con débil mano.

Tú llorarás; con lastimero acento,

Mi cuerpo besarás sobre la pira;

Tu profundo penar darás al viento.

Sentirás del dolor la cruda vira,

Porque no son de hierro tus entrañas,

Con triste llanto regarás mi lira.

Tú no fuiste engendrada en las montañas,

Ni producida de la dura tierra,

Ni creciste en las rústicas cabañas.

¿Qué zagal, qué pastora de la sierra

Secos los ojos, tornará á su casa,

Viendo la urna, que mis restos cierra?

No importunes mi sombra; el dolor pasa,

No te meses el nítido cabello,

No oscurezcas la lumbre que me abrasa.

No maltrates, oh Delia, el rostro bello,

Hasta que venga la callada muerte,

Para segar con su guadaña el cuello. 
¡Ojalá que á mi lado pueda verte

Yo te amaré, pues lo consiente el hado,

Sin miedo y sobresalto de perderte!

Ya vendrá la vejez con pié callado,

Cubierta de tinieblas la cabeza,

Y el tiempo del amor será pasado.

Hoy puedo suspirar por tu belleza,

Y la rosa coger de los amores,

Y ablandar á tu esquiva gentileza.

Estas mis guerras son, y mis dolores,

Léjos de mí trompetas y banderas,

Léjos de mí de Marte los horrores.

Busque otro gloria entre las armas fieras,

Busque nombre, grandezas y tesoro,

Yo viviré contento con mis eras,

Despreciador de la pobreza y oro.

La traducción de la elegía I 1 en cuartetos.

Otro tenga opulento plata y oro,

Yugadas mil de cultivado suelo,

Y sin cesar aquéjele el recelo

De enemigo que anhela su tesoro;

Su sueño ahuyente la guerrera trompa,

Pase mi vida sin laurel ni fama,

Arda siempre en mi hogar tranquila llama,

Lejos de mí la lid, lejos la pompa.

No deje la esperanza mis umbrales,

Mas compense del año la fatiga

En vino ardiente y en preñada espiga,

Y proteja mis tiernos recentales.

A las plantas daré sabroso riego,

Frutales plantará mi diestra mano,

De alegres vides ornaráse el llano,

Fértil la tierra escuchará mi ruego.

Veloz aguijaré los tardos bueyes,

Y si el balido de la oveja suena,

O el cabritillo por su madre pena,

Los llevaré en mis hombros a sus greyes.

En la estación de frutos precursora

Lustro aquí religioso mis pastores,

Y baño en leche y entretejo en flores

El ara de la Diosa labradora.

Pues en el rudo tronco la venero,

$Y$ humilde imploro su favor divino

En la vetusta piedra del camino 
Que marca de dos tierras el lindero.

De espigas, Ceres, tejeré corona

Que de tu templo ante los postes penda,

Y al Dios agricultor haré la ofrenda

De cuanto fruto el año nos endona.

Y en los huertos pomíferos, inmundo,

La diestra armada de segur tajante,

Príapo, ahuyentará la grey volante,

Con forma obscena y rostro rubicundo.

$\mathrm{Y}$ a vosotros, oh dioses familiares

Que protegéis mi hacienda todavía,

Hoy tan menguada si opulenta un día,

Dones ofreceré, rústicos Lares.

Propicios aceptad, númenes, todo,

Aunque de pobre mesa en frágil vaso

Que labrador antiguo, de arte escaso,

Fabricó para sí de tenue lodo.

¡Oh ladrones, oh lobos carniceros,

Os ruego perdonéis a mi ganado;

Otro redil os dé botín colmado,

Buscad para la presa otros senderos!

No ansío de mis padres la riqueza,

Ni la opulenta troj de mis abuelos;

Pobre mies satisface mis anhelos.

Descanse en pobre lecho mi cabeza.

Me es dulce oír el Aquilón sonante

Y a mi amada estrechar, mientras él ruge,

Cuando a su embate poderoso cruje

Mi combatido techo vacilante...

Y cuando lance el Austro sus corrientes

Y desborde los cauces espumosos,

Arrullarán mi sueño cadenciosos

De la perenne lluvia los torrentes.

Si reina acaso la inclemencia estiva,

Del fiero Can el hálito abrasado

Esquivaré, a la sombra recostado,

Por do murmura el agua fugitiva.

¡Antes perezcan esmeraldas y oro,

Que suspire por mí mi triste amante,

Cuando me entregue al piélago inconstante,

Ni sus mejillas humedezca el lloro!

A ti, oh Mesala, bélica prudencia

Pertenece mostrar por tierra y mares,

En despojo trayendo a tus hogares

De cien vencidos pueblos la opulencia.

Mas yo cautivo en tus hermosos ojos,

Oh Delia, estoy, y ante tu puerta dura

Alegre me consumo en vida oscura 
Por solo un beso de tus labios rojos.

Y cuando llegue a mí la hora postrera

Véate yo postrada ante mi lecho,

Con lamento que hiera el alto techo,

Derramar una lágrima sincera.

Y llamando a los dioses, aunque en vano,

Cuando se extinga mi postrer aliento,

¿Que pueda yo en el último momento

Asirme a ti con moribunda mano!

Tú llorarás sobre la alzada pira,

Triste beso a las lágrimas mezclando;

Que no es de pedernal tu pecho blando,

$\mathrm{Ni}$ tus entrañas como férrea vira.

No importunes mi sombra; el dolor pasa;

No maltrates, oh Delia, el rostro bello,

No te meses el nítido cabello,

No oscurezcas la lumbre que me abrasa.

Hoy puedo suspirar por tu belleza,

Hoy te amaré, pues lo consiente el hado;

Ya vendrá la vejez con pie callado,

Cubierta de tinieblas la cabeza.

Aun brilla la estación de los amores,

De alegres risas y lascivo fuego;

Aun las puertas quebranto en blando juego;

Estas mis guerras son y mis dolores.

Lejos de mí clarines y banderas,

Gloria buscad, grandezas y tesoro;

Despreciador de la pobreza y oro,

Yo viviré contento con mis eras. 